IJRMMS-D-13-00141 - edited and approved by editor

Technical Note

\title{
True-triaxial apparatus for simulation of hydraulically fractured multi- borehole hot dry rock reservoirs
}

\author{
Luke P. Frash*, Marte Gutierrez and Jesse Hampton \\ Colorado School of Mines, Department of Civil and Environmental Engineering, 1610 Illinois \\ St., Golden, CO 80401, USA \\ * corresponding author: \\ E-mail adresses: $\underline{\text { frash@mines.edu }}$ \\ telephone: 1 (303) 305-8834
}

Key Words: True-triaxial; hydraulic fracturing; Enhanced Geothermal Systems; EGS; drilling; Hot Dry Rock; HDR

\section{Introduction}

Drilling and stimulation are instrumental tools for underground injection and extraction of fluids for geo-environmental applications (e.g., $\mathrm{CO}_{2}$ geological sequestration) and energy extraction (e.g., oil, gas or geothermal energy production). These tools have been proven successful for both traditional high permeability reservoirs and unconventional low-permeability resources (e.g., shale-gas formations). However, current methods become increasingly challenging and unreliable when implemented in deeper, hotter and more difficult geological resources.

It is well known that subsurface rock is subjected to stresses created by overburden, 3D stress-strain interactions, tectonic activity, and other geologic processes. The associated 3D stress state can be described in tensor form by the magnitudes and orientations of the maximum, intermediate and minimum principal stresses. All three principal stresses are important in the mechanical behavior of the rock. True-triaxial equipment [1,2] was developed to simulate an 
environment where the three principal stresses have different magnitude. This is not to be confused with conventional triaxial equipment which is only capable of applying two different principal stress magnitudes.

Relevant to reservoir stimulation using hydraulic fracturing, it is expected that fractures preferentially propagate perpendicular to the minimum principal stress while the intermediate and maximum principal stresses influence fracture length and height [3,4,5]. Many mathematical models relating pressures, rock stresses, geometry, and rock properties have been developed for understanding hydraulic fracture initiation (breakdown) pressures $[6,7,8]$ and created fracture dimensions [4,9]. The models are actively being improved and new models are in development to better handle the complexities of real rock, multi-phase fluids and thermal systems. Therefore, new controlled experimental testing is needed at the laboratory scale to provide physical data to validate the models and to better understand the associated behavior. Specifically, there is a need for physical data from Hot Dry Rock (HDR) applications which is of interest to the advancement of Enhanced Geothermal Systems (EGS) technology.

A new true-triaxial apparatus capable of simulating multi-borehole drilling and hydraulic

fracturing in $300 \times 300 \times 300 \mathrm{~mm}^{3}$ heated rock specimens was recently developed in an effort to perform this laboratory testing. Initial testing was directed towards the study of EGS in an effort to validate its potential in crystalline HDR reservoirs having no significant in-situ permeability or porosity. This paper presents the features and details of this new heated true-triaxial device and presents results from a granite specimen test. For this test a binary injector-producer scheme was applied using hydraulic fracturing to create a permeable pathway between two oriented boreholes.

\section{Heated True-Triaxial Equipment}

The new apparatus, shown in Fig. 1, consists of a heated true-triaxial apparatus, a drilling apparatus, a hydraulics system, and an instrumentation system. Fully assembled, the equipment possesses following list of features and capabilities: (1) confining stresses up to $13 \mathrm{MPa}$; (2) externally applied zonal heating up to $180{ }^{\circ} \mathrm{C}$; (3) continuous fluid injection rates from 10 to 60 $\mathrm{mL} / \mathrm{min}$; (4) constant pressure injection with proportional-integral-derivative (PID) control at pressures up to $70 \mathrm{MPa}$; (5) high viscosity fluid and proppant-laden slurry injection; (6) oriented multiple-borehole drilling at reservoir conditions; (7) digital monitoring of pressure, temperature, 
and flow rate; (8) specimen strain and temperature monitoring; and (9) acoustic emission (AE) monitoring with source location.

\subsection{True-Triaxial Apparatus}

A multitude of designs for true-triaxial equipment are available in the literature [1-3, 1019] with application in geomechanics research and material characterization. The associated rock specimens are typically rectangular blocks or cylinders. True-triaxial loading is typically applied through rigid platens, flexible bladders and passive confinement (e.g., steel casing). Of all the existing designs, none were found completely adequate for simulation of drilling multi-borehole systems in HDR conditions.

The new apparatus, shown in Fig. 2, was designed with a mixed flexible bladder (flat jack) and passive confinement system capable of supporting a cubical rock specimen no larger than $300 \times 300 \times 300 \mathrm{~mm}^{3}$. The typical apparatus' configuration applies each principal stress via one active hydraulic flat jack per principal axis. Specimen faces directly loaded by the flat jacks and the opposing reaction faces supported by the frame are hereby referred to as active and passive faces, respectively. The steel top lid was furnished with a $63 \mathrm{~mm}$ diameter port to pass electrical sensor wires and hydraulic tubing for the contained sensors and flat jacks. The outer reaction ring of the cell was constructed from A36 structural steel with minimum yield of 250 MPa. The lids were constructed with A514 steel with minimum yield of $700 \mathrm{MPa}$, reducing thickness requirements for stress design criteria. Sufficient thickness was provided to permit drilling multiple non-intersecting $10 \mathrm{~mm}$ holes through the lid while maintaining a safety factor of no less than 2.0. Collectively these design elements reduced the cost of fabrication which was important when considering that the structural elements would require replacement after drilling holes eventually compromises the structural integrity.

Active face stresses are provided by commercially available $350 \mathrm{~mm}$ diameter circular flat jacks (selected due to budget) and an assembly of two $300 \mathrm{~mm}$ diameter round steel platens and one $300 \mathrm{~mm}$ square steel platen. Each flat jack is pressurized via an independent hand pump with active digital pressure monitoring. Using separate pumps bypasses pressure control issues which occur in single pump systems with valves; hydraulics tend to leak somewhere and valves displace fluid. The square platen's inward edges were beveled to mitigate binding with adjacent platens. A $25 \mathrm{~mm}$ thickness was specified for the square platens referencing basic elastic analysis 
evaluating the stress transmission over the corners. The square platen doubled as a protective housing for $\mathrm{AE}$ sensors improving $\mathrm{AE}$ data quality and reducing assembly time. A typical alternative AE sensor installation method in similar true-triaxial devices involves cutting shallow holes into the specimen with consequentially increased sensor alignment difficulty, increased preparation time, decreased stress uniformity, and potentially increased AE measurement errors.

Passive faces were supported by a steel platen on the vertical axis and cast-in-place concrete platens on the horizontal axes. The initial design included steel passive platens for all three axes but preliminary testing revealed that tolerances resulted in poor stress uniformity and difficult assembly with this approach. A concrete grout mix with a working time of 6 to 24 hours was poured into plastic bags that filled the voids on the passive faces. While the concrete remained plastic, the top lid was rapidly installed and a seating vertical stress of 0.1 to $0.5 \mathrm{MPa}$ was applied. The concrete required at least $24 \mathrm{hrs}$ cure time to sufficiently strengthen before full stress application. Experiments performed using the concrete platens were found to give acceptable stress uniformity through specimen strain gage measurements and AE source distributions during flat jack pressurization. A focused stress calibration was also performed using pressure sensitive film.

The three-flat-jack method was selected for the basic configuration because it permitted drilling multiple oriented boreholes through the three passive faces of the specimen at orientations ranging from vertical to horizontal. EGS reservoir simulation requires flexibility in borehole placement when fracture-intercepting boreholes are drilled after hydraulic fracture stimulation. Passive faces also enabled drilling at HDR conditions which better simulates the field and minimizes complications arising from alternative methods which introduce thermal cycling and cyclic loading. A popular alternative design provides one square flat jack per face of the specimen and requires a specialized open-centered flat jack on the top face for borehole passage. This loading method is expected to produce improved stress uniformity especially when any platens between the flat jack and rock specimen are thin or flexible. In this case, the top flat jack option was too limiting for multi-borehole EGS reservoir simulation. Opposing horizontal axes flat jacks remain an option for the new true-triaxial apparatus and could readily be implemented given the large $63 \mathrm{~mm}$ diameter port on the top lid for passage of hydraulic lines. Initial experiments performed with the apparatus have not utilized the opposing flat jack option. 


\subsection{Heating System}

Heating of the specimen is provided by flexible electrical elements mounted on the external surface of the reaction frame. Two $900 \mathrm{~W}$ parallel heating elements were mounted on the cylindrical body giving approximately $1800 \mathrm{~W}$ of lateral heating capacity. An additional 750 $\mathrm{W}$ round heating element was mounted on the bottom plate. Dual-zone PID control allowed different temperature set-points for the lateral and bottom elements. Firebrick insulation enclosed the whole assembly while heated, improving safety and reducing thermal losses.

\subsection{Drilling Apparatus}

Oriented boreholes are drilled into the rock specimen through the true-triaxial reaction frame and any intersecting passive platens. Boreholes are drilled using a custom rotary hammer drill press (Fig. 1) that can be mounted anywhere on the top of the cell, provided the trajectory does not intersect any of the flat jacks or critical internal sensors. The orientation and rate of penetration are controlled via a screw-actuated shuttle with selectable vertical deviation angles of $0^{\circ}, 15^{\circ}, 30^{\circ}$ or $45^{\circ}$. Rotary-only mode was used for drilling through steel and rotary-hammer mode, with a masonry drill bit, was typically used for drilling through concrete and rock. The percussive drilling action with rotary-hammer mode increases the rate of penetration through the rock specimen and is also expected to develop a damage zone in the near wellbore region. Nearwellbore damage due to drilling is expected in field wells. It is anticipated that having near wellbore damage could influence the hydraulic fracturing process, as predicted by linear elastic fracture mechanics, but a quantitative evaluation of this phenomenon has not yet been performed. Millimeter accuracy of borehole alignments is possible with this drilling rig.

\subsection{Borehole Fluid Injection/Production System}

A diagram of the borehole fluid injection and production system is provided in Fig. 3. Dual TELEDYNE ISCO ${ }^{\circledR} 65$ DM syringe pumps, a computer controlled valve system, a rotationally mixed accumulator, and a high pressure borehole sealing system allow for the controlled injection of clean fluid or slurry into a rock specimen for both reservoir flow and stimulation purposes. A vacuum pump and condenser system is used for pumping fluids from production boreholes during fluid circulation testing. 
Injection borehole fluid pressures and flow rates are precisely controlled using a custom LABVIEW $^{\circledR}$ program to communicate with the syringe pump controller. This program features simultaneous continuous data acquisition and sub-programmable control of the pumps and valves. Current pumping sub-programs include the control functions: (1) continuous constant flow rate injection; (2) continuous constant PID controlled pressure injection; (3) stepped constant pressure or stepped constant flow rate injection; (4) conditional pump operation; (5) real time referencing to externally collected data; (6) multi-day operation with uninterrupted $1 \mathrm{~Hz}$ appending data output; (7) clock time referencing for multi-system synchronization; (8) real-time pump status graphical display with history plotting; (9) internalized editing while the main program is running to prevent real-time data loss; and (10) automated switching from clean to slurry fluid injection. The physical capabilities of the injection system included a pressure range of 0 to $70 \mathrm{MPa}$ gage and a flow rate range of 10 to $60 \mathrm{~mL} / \mathrm{min}$.

The automated valve system was constructed from pneumatically-operated hydraulic valves which were operated by a chain of components ultimately controlled by the same program used to operate and monitor the syringe pumps. As shown Fig. 3, a horizontal-axis rotationallymixed piston accumulator with high pressure rotary fittings was used to inject proppant slurry into the borehole. The proppant concentration is controlled by rotating the accumulator at experimentally determined homogenous mixing speeds. The one liter capacity accumulator was operated in a fluid-fluid mode, rather than the more common fluid-gas mode for such devices, to allow for the device to act as a high pressure storage chamber and fluid transfer mechanism.

The injection borehole is sealed for high pressure fluid injection and hydraulic fracture stimulations using the method shown in Fig. 4. The upper borehole was cased with 3/8 in $(9.52$ $\mathrm{mm}) 316$ stainless steel tubing installed into a $10 \mathrm{~mm}$ diameter borehole and grouted in place using epoxy. To enhance the strength of the seal, the tubing was externally threaded with a 3/816 hand die to a partial depth where a rough flat tipped thread was produced. Epoxy grout was delivered into the borehole with size 00 gelatin capsules filled with a measured quantity of premixed two-part epoxy sufficient to fill the annulus between the tubing and the borehole wall. The capsules were broken at the bottom of the borehole using the tubing with a pre-installed epoxy plug sealing the bottom end. This installation method prevents accidental bondage of the tubing to the true-triaxial equipment. A nominal $5.6 \mathrm{~mm}$ diameter uncased hydraulic fracturing interval was drilled to the desired borehole depth after the epoxy was fully cured. This method was 
experimentally proven to seal high-pressure fluid in a granite rock specimen at more than 49 $\mathrm{MPa}$. Other methods, such as concrete grouting, were found to be unsuccessful and unreliable.

A different sealing method and pumping system were used for the production borehole. These included a vacuum pump and a steam condenser which were not intended for high pressure fluids. For this system, a ferrule was installed onto a section of $1 / 4$ in $(6.35 \mathrm{~mm})$ O.D. nylon tubing that was seated into a section of larger $3 / 8$ in $(9.52 \mathrm{~mm})$ O.D. vinyl tubing to form an expansive seal onto a $10 \mathrm{~mm}$ nominal diameter borehole wall. This seal is further enhanced using vacuum grease such that sustained vacuum pressure could be applied to an interval of the production borehole and the produced fluid could be pumped out. A digital mass balance was used to monitor and record the mass of the produced water stored in the condenser.

\subsection{Instrumentation System}

In addition to the flow rate and pressure data obtained from the syringe pump controller, an array of sensors and four data acquisition systems were utilized. The monitoring system allowed for the collection of temperature, pressure, strain, and acoustic emission data to monitor and characterize the hydraulic, mechanical, electrical, and acoustic response of the reservoir during testing. The system was built to be extensive and easily modified to allow for as much data as possible to be collected during reservoir testing. This large database was in turn usable to formulate comparisons between laboratory data, field data, and modeling results.

A list of the sensors used to monitor the reservoir is provided in Table 1 along with a brief description of the sensors, their respective applications, measurement range and accuracy. In general, sensor accuracies were not found to be an issue during preliminary experiments because heterogeneities, unknowns about the fracturing process, and other issues led to even greater uncertainties. The positions of these sensors during testing were typically arranged as shown in the fold-out diagram provided in Fig. 4 and the hydraulic diagram in Fig. 3. Confining pressure, wellhead pressure, fluid temperatures, reservoir temperatures, and specimen strain data were all acquired by a National Instruments (NI) data acquisition system through a series of LABVIEW ${ }^{\circledR}$ programs.

Acoustic signals, correlated with fracture growth, location, and geometry, were monitored using a Physical Acoustics Corporation (PAC) AE monitoring system with six WS $\alpha$ sensors and three PCI-2 cards. These sensors were attached directly to the sample faces, with a 
thin layer of vacuum gel for coupling, to attain direct AE measurements with minimal reflection, surface interference, sensor orientation error, or attenuation affects. The use of six sensors also enabled the application of moment tensor analysis to classify recorded AE events according to the mode of failure as tensile dominated, mixed-mode, or shear dominated. Simplified moment tensor analysis [20] requires p-wave first arrival characteristics at a minimum of six locations to calculate the six unknown components of the respective moment tensor solution. The accuracy of this approach improves when positioning the sensors around the volume of interest at varying orientations and with maximal volumetric coverage. Placing the sensors near the corners of the specimen (Fig. 5) and including orientations parallel to all principal axes optimizes the six sensor system to produce data with sufficient quality for simplified moment tensor analysis. AE data quality was further improved when a buffer layer of open cell foam was provided to isolate the sensor body from the steel platen housing. Specimen materials used in preliminary experiments exhibited low attenuation and nearly-isotropic acoustic velocity which enabled this simplified analysis to be successful.

\section{Test Procedures}

A typical test setup for the simulation of an EGS reservoir will be described to provide an overview of how the equipment is used. A complete reservoir simulation test can generally be described according to the three stages of: (1) sample preparation; (2) reservoir simulation; and (3) post-test analysis. The specific procedures used in each of these stages are described following the same sequential order as they would be applied. The typical reservoir simulation experiment performed with this equipment is long in duration to reduce risk of thermal cracking during heating, to allow for epoxy and concrete cure times (typically 24 hours or less), and to execute the hydraulic fracture stimulations, reservoir flow tests, and re-stimulations necessary for thorough EGS reservoir evaluation. Preliminary tests have lasted from 3 to 90 days.

\subsection{Rock Specimen Preparation}

The following typical steps are used for rock specimen preparation: (1) the rock specimen is prepared to the nominal dimensions of $300 \times 300 \times 300 \mathrm{~mm}^{3}$ with a surface tolerance of \pm 0.5 $\mathrm{mm}$, perpendicularity of $\pm 1^{\circ}$, and higher homogeneity preferred; (2) instrumentation is installed on the specimen and sensor wires are routed to the corners or edges of the sample; (3) active face 
steel platens and flat jack assemblies are installed into the cell while the top lid is removed, as shown in Fig. 2; (4) the rock specimen is carefully lowered into the cell and pressed into the flat jack assemblies to close tolerance gaps; (5) the passive concrete platens and top lid are installed; (6) a vertical seating stress of less than 0.5 MPa is applied; (7) the rock specimen is heated to the target temperature at a rate no higher than $10^{\circ} \mathrm{C}$ per day; (8) target confining stresses are applied at proportional increments of more than $0.7 \mathrm{MPa}$; and (9) stresses and temperatures are monitored continuously for at least 48 hours to verify equilibrium. Rock specimens with poor surface tolerance can be covered with a thin molded layer of non-shrink concrete to improve uniformity of stress transfer. Preliminary experiments using this gap filling technique were found to provide improved stress uniformity through strain gage measurement.

\subsection{Reservoir Stimulation}

Reservoir simulation is performed after the targeted HDR conditions are applied and equilibrated. Typical reservoir simulation is performed as follows: (1) the injection borehole is drilled along the desired trajectory; (2) casing is installed into the borehole and the respective epoxy grout allotted at least 24 hours to cure; (3) pre-stimulation constant $2 \mathrm{MPa}$ injection is performed to evaluate initial reservoir permeability and leak check the hydraulic lines; (4) hydraulic fracture stimulation is performed; (5) AE source location data is used to estimate the induced fracture geometry and a fracture intercepting production borehole alignment is selected; (6) the borehole is swabbed to check for successful fracture interception by evidence of fracturing fluid; (7) hydrothermal flow testing experiments are performed to characterize the reservoir behavior; and (8) additional stimulation treatments and flow testing is performed as necessary to produce a functional EGS reservoir.

Preliminary experiments identified that an initial injection rate of $0.05 \mathrm{~mL} / \mathrm{min}$ was suitable for creating hydraulic fractures fully contained within the confines of most $300 \mathrm{~mm}$ rock specimens. Faster rates could be applied if the initial injection failed to stimulate a hydraulic

fracture. These faster rates are typically necessary for rock specimens with higher permeability or higher fracture toughness, as could be predicted by combining fracture initiation theory with transient flow theory for porous media.

Hydrothermal flow testing typically included a series of injection-production tests with constant pressure or constant flow rate control. Injections were performed as single stage tests or programmed stepped interval tests. These characterization tests were performed before and after 
each new stimulation or re-stimulation. The specific characterization tests for a given experiment were selected based upon the observed reservoir behavior and the experimental variables being investigated.

\subsection{Post-test Analysis}

The true-triaxial apparatus is unloaded after completion of reservoir simulation using the following procedure: (1) true-triaxial stresses are released; (2) temperatures are reduced to ambient at no greater than $10^{\circ} \mathrm{C}$ per day; (3) the top lid and top passive platen are removed; (4) the rock specimen is slowly ejected from the cell using an auxiliary hydraulic jack and platen system; and (4) the specimen is inspected. This procedure ensures minimal secondary damage to the specimen and overcomes residual stresses incurred from any plastic deformation of the lateral flat jacks. The recovered rock specimen is typically cut into thin horizontal slices for cross-sectional imaging and geometric measurement of the stimulated fractures. Alternatively, non-destructive techniques (e.g., computed tomography imaging) could be used at expectedly higher cost.

The specific procedure applied for a given test varies according to the relevant experimental objectives and observed conditions. Data acquisition is continuously active through all stages, when possible, to capture any events which occur from initial assembly through to final disassembly. This method ensures that thermally induced fractures, creep phenomena, and other secondary processes to stimulation and flow are captured and identified. This approach enabled multi-day testing and was implemented into the custom data acquisition programs with time synchronization provided for comparison between all gathered data types.

\section{True-Triaxial Calibration}

A notable consequence of the three-flat-jack design used for this true-triaxial apparatus is the potential for increased frictional effects between the rock specimen and platens. Friction is known to affect stress uniformity which is of critical concern for conventional true-triaxial testing (e.g., evaluation of material yield criterion in anisotropic stress conditions). Rock stresses are also important in EGS and reservoir simulation because they are known to be the dominant factor controlling hydraulic fracture growth. Specifically, principal stress directions control fracture propagation direction and stress magnitudes affect fluid pressures and flow. The rock 
specimen stress conditions relevant to preliminary experiments performed with this true-triaxial apparatus were evaluated using computer modeling, a physical calibration test, and strain gage measurement.

\subsection{Finite Element Stress Modeling}

Finite Element (FE) modeling was performed to evaluate the combined effects of friction, AE sensor housings, unloaded edges, and platen corners on the stresses inside the rock specimen. The model was constructed as shown in Fig. 5 with geometry and materials matching the real true-triaxial apparatus. The steel comprising the loading plates and the cell assembly were assigned an elastic modulus of $200 \mathrm{GPa}$ and a Poisson's ratio of 0.26 representing ASTM A36 mild steel. The rock specimen was modeled as granite with an elastic modulus of $56.9 \mathrm{GPa}$ and a Poisson's ratio of 0.32 . Loading was applied with a constant force boundary condition on the 300 $\mathrm{mm}$ diameter round platens to induce a targeted average rock specimen stress state of 13,8 , and $4 \mathrm{MPa}$ for the vertical and horizontal directions respectively. The same targeted stresses were applied during preliminary laboratory experiments. Multiple simulations were performed to evaluate the effect of friction along the platen-rock interface. Frictional coefficients of 0.005 , 0.02, and 0.30 were assigned to represent states of negligible friction, two-layer Teflon sheets with silicone grease [21], and typical steel-steel contact, respectively. A fully bonded model representing a maximal frictional condition was also analyzed. All numerical simulations were performed using SolidWorks ${ }^{\circledR}$ Simulation.

Hydraulic fracturing for EGS is intended to target deep reservoirs (e.g., 3 to $10 \mathrm{~km}$ ) which are reasonably assumed to have pseudo-infinite lateral extent for modeling purposes. A discrete reservoir boundary is inherent to laboratory simulation but boundary effects can be minimized if created hydraulic fractures are fully contained within the confines of the rock specimen. Optimal placement of an injection borehole for producing contained fractures would therefore be the center of the specimen. Fig. 6 provides a plot of the FE results for the minimum horizontal stress along a line traversing vertically through specimen's center. These results indicate clamping stresses near the boundaries which could potentially aid in hydraulic fracture containment. They also indicate a non-uniform stress distribution with the most significant stress deviations near the active face. The platen corners and AE sensor housings were the prominent factor affecting stress uniformity on the active faces. Stresses were more uniform through the 
center of the specimen up through the interception of the passive face. Frictional effects were found to be negligible for the minimum horizontal stress state implying that use of Teflon sheets would have little effect on hydraulic fracture propagation.

Figure 7 presents a plot of the modeled vertical and horizontal normal stresses with an assigned friction coefficient of 0.30 . These results indicate that the principal stress directions were consistent through the rock specimen, which is important for fracture propagation and final geometry. All three stress axes exhibited relatively uniform distribution near the center of the specimen.

\subsection{Strain Gage Measurement}

Specimen strain gage data was acquired during preliminary experiments performed with this true-triaxial apparatus. The configuration of the surface mounted gages varied with each experiment depending upon the given objectives. Fig. 4 presents one strain gage configuration where rosettes were installed on two corners and three faces of a granite specimen. The locations were systematically set on mostly passive faces with the intent of evaluating stress uniformity during loading in these critical areas. Less than $80 \%$ of the installed gages provided reliable data when implemented because of incidental damage during installation and assembly. Similar strain gage damage issues were encountered in all other experiments using the true-triaxial apparatus despite procedural modifications to protect the fragile instruments. The operational gages indicated improved stress uniformity when thin layers of concrete were applied on the specimen faces to improve tolerances and when passive concrete platens were used instead of steel passive

platens. Strain responses were also recorded during hydraulic fracturing and hydrothermal flow testing. In some cases, the hydraulic fractures intercepted strain gages providing additional information about the stimulated fracture geometry as a function of time.

\subsection{Design Rationale}

The motivation for using $350 \mathrm{~mm}$ diameter flat jacks with $300 \mathrm{~mm}$ square steel platens was dominantly budgetary. Modifying the apparatus to a $300 \mathrm{~mm}$ square flat jack system would be a simple task and would mitigate most of these undesired stress concentration issues. Preliminary experiments did not utilize specialized friction reduction options such as Teflon sheets. The sheets were expected to increase difficulty of assembly and induce errors in AE data 
through refraction and reflection through the additional material interface. The benefit to stress uniformity in the minimum principal stress plane, being the expected hydraulic fracture propagation plane, was expected to be less important than attaining higher quality AE data.

\section{Results from Scale Model Simulation of EGS Reservoir Creation in Granite}

A laboratory simulation of an EGS reservoir was completed to validate this true-triaxial apparatus and its hydraulic fracturing, fracture intercept borehole drilling, and hydro-thermal flow functionalities. Colorado Rose Red Granite (Fig. 4) was selected as the specimen material to simulate the creation of an EGS reservoir in a heated impermeable crystalline rock. The material parameters for this granite were measured from index and element tests giving the values provided in Table 2. The test specimen was heated to $50{ }^{\circ} \mathrm{C}$ and subjected to confining stresses of $12.5,8.3$, and 4.1 MPa for the vertical, maximum and minimum horizontal stresses, respectively. The low permeability of this granite was expected to result in a reservoir with minimal leak-off. A successful reservoir simulation required a hydraulic connection between the injection and production boreholes via hydraulic fracture.

\subsection{Borehole Drilling and Initial Hydraulic Fracture}

An EGS reservoir was created using a binary borehole injector-producer layout. The two boreholes in this test included a centered vertical injection borehole and an offset oriented production borehole. The boreholes were percussively drilled while the test specimen was maintained at reservoir conditions. The injection borehole was drilled first having an upper 107 $\mathrm{mm}$ deep by $10 \mathrm{~mm}$ diameter cased interval and a lower $74 \mathrm{~mm}$ long by $5.6 \mathrm{~mm}$ diameter uncased interval, giving a total drilled depth of $181 \mathrm{~mm}$. Hydraulic fracturing was performed through this borehole with the injection of Valvoline ${ }^{\circledR}$ Durablend $^{\circledR}$ SAE 80W90 gear oil at 0.05 $\mathrm{mL} / \mathrm{min}$. The oil viscosity at $50{ }^{\circ} \mathrm{C}$ was estimated at $72 \mathrm{cP}$ per manufacturer's data and ASTM D341 [22].

$\mathrm{AE}$ events recorded during stimulation were used to estimate the position of the created hydraulic fracture. A production borehole alignment was selected to intercept this fracture as shown in Fig. 8. The production borehole was drilled on the maximum horizontal stress plane (xz-plane) and the dimensions were measured at $252 \mathrm{~mm}$ long with $10 \mathrm{~mm}$ diameter and an angle of $30^{\circ}$ from the vertical axis. It was positioned $58 \mathrm{~mm}$ from the injection borehole, measured 
parallel with the maximum horizontal stress axis ( $y$-axis). The hydraulic fracture was intercepted at an estimated depth of $118 \mathrm{~mm}$. The recovery of hydraulic fracturing oil with a borehole swab verified that the hydraulic fracture had been successfully intercepted.

Figure 9 provides the hydraulic data plot for the hydraulic fracturing treatment where the peak-pressure was observed at $18.1 \mathrm{MPa}$ followed by forced fracture closure where the flow was

briefly reversed in an effort to contain the hydraulic fracture within the granite specimen. This breakdown pressure is greater than the theoretical [8] predicted value of $10.4 \mathrm{MPa}$ but such deviations are expected due to heterogeneity and scaling effects occurring with small diameter boreholes [23]. Similarly elevated breakdown pressures were observed during unconfined granite, concrete, and acrylic fracturing tests performed prior to this experiment.

\subsection{Geothermal Flow Tests and Re-Stimulations}

A total of thirty-one geothermal reservoir flow tests, two re-stimulation tests, and one experimental hydraulic impulse stimulation treatment were performed after drilling the production borehole. The total duration of these injection tests was roughly three months. The restimulations were deemed necessary after post-stimulation flow tests failed to produce fluid in the production borehole at a sufficiently high rate. A plot of the AE event locations from the second re-stimulation, Fig. 10, indicated that the hydraulic fracture was extended to the boundary of the reservoir. The fracture breaching the boundary of the specimen was not ideal for EGS reservoir simulation because of the added fluid leakage paths but it did have the benefit of stabilizing the fracture for geothermal flow analysis.

The injection fluid was changed from oil to tap water after the re-stimulation treatments were completed and a hydraulic connection between the injection and production boreholes was confirmed. Pure water viscosity at $50{ }^{\circ} \mathrm{C}$ is approximately $0.55 \mathrm{cP}$ [24]. Tap water was used over distilled water because distilled water was expected to be more chemically reactive. No chemical reactivity studies have been performed at this time.

Figure 11 provides a plot of the hydraulic data attained during geothermal flow testing through the reservoir. These injection based tests included constant pressure and constant flow control modes with many tests completed using computer controlled steps of incremental pressures or flow rates. Computer control improved repeatability. An example stepped test is shown in Fig. 12 where the latter $30 \%$ of each step was analyzed to attain the data presented in 
Fig. 10. The flow data was repeatable indicating negligible fracture growth during these flow tests. The stability of the fractures was further confirmed through minimal AE activity during these injection tests. Stepped constant pressure control was consistently observed to be more repeatable than stepped constant flow rate control.

\subsection{Hydraulic Impulse}

Production rates were low while injection pressures were high during the first set of flow tests performed with water. These flow rates were so low that borehole swabbing was needed to measure the production rate, giving an estimated injection rate to production rate ratio of less than $0.1 \%$. These results indicated failure to create a producing EGS reservoir. An experimental hydraulic impulse treatment was then performed in a final attempt to improve the conductivity of the reservoir. This treatment used a pressurized accumulator and a valve to inject $2.4 \mathrm{~mL}$ of water with an initial pressure of $65 \mathrm{MPa}$ and impulse duration of less than $0.2 \mathrm{sec}$. Additional details on this method have been published [25]. The result of this treatment was a two-order magnitude increase to reservoir injectivity and a boost in production flow rate.

\subsection{Geothermal Production Monitoring}

The new production rates after the hydraulic impulse were sufficient for continuous flow measurement using vacuum pumping, a condenser, and a digital mass balance. A vacuum seal was installed inside the top of the production borehole using a system of flexible vinyl tubing, a compression ferrule, nylon vacuum tubing, and silicone vacuum grease. The assembly also included a thermocouple passed through the inside of the nylon tubing for bottom-hole temperature measurement. Fig. 13 provides a plot of the production rate to injection rate ratio as a function of injection rate. This data was produced from constant flow rate injections tests having durations of no less than $60 \mathrm{~min}$. Long injection times were needed for thermal and hydraulic steady state approximations. Linear regression was applied to correct for evaporative losses from the condenser chamber and to evaluate the production flow rates. A peak fluid recovery ratio of $18 \pm 0.5 \%$ was observed at an injection rate of $0.5 \mathrm{~mL} / \mathrm{min}$. 


\subsection{Specimen Recovery and Sectioning}

The rock specimen was successfully removed undamaged after flow testing was completed. A core was removed around the borehole from the specimen to extract the steel casing as a preparation for cross-sectioning with wet diamond saw. The cross-sections were visually inspected and photographed for measurement of the hydraulic fracture geometry. A digitized representation of the fracture geometry is provided in Fig. 14. Three dominant fractures were identified giving a general structure resembling bi-wing geometry. The observed fracture geometry matches the $\mathrm{AE}$ data as seen when comparing Figs. 10 and 14. It is notable that the single dominant fracture wing identified during the first hydraulic fracture treatment, Fig. 8, did not extend to the boundary of the rock specimen while the opposing wing did. Two parallel fractures were observed between the injection and production boreholes. The first of these fractures only intersects the production borehole with the extreme edge of its extents while the second has a twisted orientation matching the production borehole alignment, directly intersecting the production borehole, and was apparently arrested by the borehole. This peculiar geometry suggests that the second fracture was created after the production borehole was drilled. It is speculated that this second fracture was created during the impulse stimulation treatment knowing high-strain rates are more likely to produce branched fractures. The flow data further supports this deduction with the significant increase in production rate after the impulse treatment.

\section{Conclusions}

This heated true-triaxial apparatus was able to simulate a functioning binary EGS reservoir created within an intact granite specimen. The simulation included drilling at reservoir conditions, hydraulic fracturing, AE guided production borehole drilling, reservoir flow analysis, re-stimulations, and experimenting with hydraulic impulse stimulation. Data produced included pressures, flow rates, temperatures, $\mathrm{AE}$, strains, and mapping of the produced fracture extents. Supplemental material parameters were also measured for the rock (e.g., Uniaxial Compressive Strength). This represents a thorough data set for a laboratory scale EGS reservoir.

Unique to this true-triaxial device is the ability to drill multiple oriented boreholes into a

reservoir specimen while heating and confining stresses are actively applied. This capability permits the laboratory simulation of many injector-producer layouts and provides an opportunity 
to evaluate their effectiveness in real rock. The performance of this apparatus can benefit from known modifications to the flat jack assemblies but unfortunately these options were beyond budgetary limits.

The results from this experiment demonstrate that: (1) an EGS reservoir can be created within an intact crystalline rock reservoir; (2) AE source locations can be used to accurately locate a hydraulic fracture for production borehole drilling; (3) re-stimulations can be used to increase the hydraulic connectivity between injection and production boreholes; (4) high fluid losses can be expected in positive net-pressure binary borehole systems, where this experiment gave a maximum production rate to injection rate ratio of 18\%; and (5) frictional fluid pressure losses through hydraulic fractures are significant and cannot be neglected. An experimental hydraulic impulse stimulation treatment was also implemented during this experiment with high success. The impulse resulted with a significant increase to hydraulic fracture conductivity and required minimal time to execute. Further analysis of the results from this experiment could draw additional conclusions but such work is beyond the scope of this paper.

\section{Acknowledgements}

Financial support provided by the U.S. Department of Energy under DOE Grant No. DEFE0002760 is gratefully acknowledged. The opinions expressed in this paper are those of the authors and not the DOE. 


\section{References}

[1] Mogi K. Experimental Rock Mechanics. New York: Taylor \& Francis; 2007.

[2] Kwaśniewski M, Li X, Takahashi M. True Triaxial Testing of Rocks. AK Leiden: CRC Press; 2013.

[3] Johnson E, Cleary MP. Implications of Recent Laboratory Experimental Results for Hydraulic Fractures. In: Proceedings of the SPE Low Permeability Reservoirs Symposium. Denver; 15-17 April 1991. p. 413-28.

[4] Perkins TW, Kern LR. Widths of Hydraulic Fractures. J. Petrol. Technol. 1961; 13(9):937-49.

[5] Warpinski NR, Clark JA, Schmidt RA, Huddle CW. Laboratory Investigation on the Effect of In-Situ Stresses on Hydraulic Fracture Containment. SPE J. 1982; 22(3):333-40.

[6] ASTM Standard D4645-08: Standard Test Method for Determination of In-Situ Stress in Rock Using Hydraulic Fracturing Method. In: Annual Book of ASTM Standards. West Conshohocken: ASTM International; 2008.

[7] Herget G. Stress in Rock. Rotterdam: Balkema; 1988.

[8] Valkó P, Economides M. Hydraulic Fracture Mechanics. New York: Wiley; 1995.

[9] Warpinski NR, Moschovidis ZA, Parker CD, Abou-Sayed IS. Comparison Study of Hydraulic Fracturing Models - Test Case: GRI Staged Field Experiment No. 3. SPE Prod. \& Fac. 1994; 9(3):7-16.

[10] Behrmann LA, Elbel JL. Effect of Perforations on Fracture Initiation. J. Petrol. Technol. 1991; 25(5):608-15.

[11] Bo Ibsen L, Praastrup U. The Danish Rigid Boundary True Triaxial Apparatus for Soil Testing. ASTM Geotech. Test. J. 2002; 25(3):254-65.

[12] Chrisholm J, Fisher K, Abass H, Warpinski N, Baree B, Crafton, J, at al. Near Wellbore Hydraulic Fracture Mechanics. Houston: ProTechnics; 1994.

[13] Coccia C, McCartney J. A Thermo-Hydro-Mechanical True Triaxial Cell for Evaluation of the Impact of Anisotropy on Thermally Induced Volume Changes in Soils. ASTM Geotech. Test. J. 2012; 35(2). 11 p.

[14] Daneshy AA. Experimental Investigation of Hydraulic Fracturing Through Perforations. J. Petrol. Technol. 1973; 25(10):1201-6.

[15] de Pater CJ, Cleary MP, Quinn TS, Barr DT, Johnson DE, Weijers L. Experimental Verification of Dimensional Analysis for Hydraulic Fracturing. SPE Prod. \& Fac. 1994; 9(4):230-8.

[16] Ishida T, Chen Q, Mizuta Y, Roegiers J. Influence of Fluid Viscosity on the Hydraulic Fracturing Mechanism. J. Energ. Resour. Technol. ASME 2004; 126:190-200.

[17] Rawlings CG, Barton NR, Bandis SC, Addis MA, Gutierrez MS. Laboratory and Numerical Discontinuum Modeling of Wellbore Stability. J. Petrol. Technol. 1993; 45(11):1086-92. 
[18] Wieland CW, Miskimins JL, Black AD, Green SJ. Results of a Laboratory Propellant Fracturing Test in a Colton Sandstone Block. In: Proceedings of the SPE ATCE. San Antonio; 25-27 September 2006. 9 p.

[19] Zoback MD, Rummel F, Jung R, Raleigh CB. Laboratory Hydraulic Fracturing Experiments in Intact and Pre-Fractured Rock. Int. J. Rock Mech. Min. Sci. 1977; 14:4958.

[20] Ohtsu, M. Acoustic Emission Theory for Moment Tensor Analysis. Res. Nondestr. Eval. 1995; 6:169-84.

[21] Demiris CA. Investigation of Boundary Friction Effects in Polyaxial Tests. ASTM Geotech. Test. J. 1987; 10(2):86-90.

[22] ASTM Standard D341-09: Standard Practice for Viscosity-Temperature Charts for Liquid Petroleum Products. In: Annual Book of ASTM Standards. West Conshohocken: ASTM International; 2009.

[23] Haimson BC, Zhao Z. Effect of borehole size and pressurization rate on hydraulic fracturing breakdown pressure. In: Proceedings of the $32^{\text {nd }}$ USRMS. Norman; 10-12 July 1991;191-99.

[24] White FM. Fluid Mechanics. Boston: McGraw-Hill; 2008.

[25] Frash L, Gutierrez M, Hampton J. Experimentation with Hydraulic Impulse Stimulation in a Scaled Enhanced Geothermal Systems Reservoir. In: Proceeding of the $47^{\text {th }}$ USRM/GMS. San Francisco; 23-26 June 2013;975-86. 


\section{List of Tables}

Table 1 - List of sensors used during experimentation with their ranges and accuracies.

Table 2 - Material properties for Colorado Rose Red Granite. 


\section{List of Figures}

Fig. 1. True-triaxial apparatus with brick insulation (left) and orientated drilling rig (right).

Fig. 2. Interior of the true-triaxial apparatus showing platen and jack assemblies.

Fig. 3. Borehole hydraulics system showing the pump reservoir (a), remote control valves (b), syringe pumps (c), mixed slurry reservoir (d), stimulated rock specimen (e), vacuum condenser (f), high pressure sealed injection borehole (g), and vacuum pressure sealed production borehole (h).

Fig. 4. Sensor placements on the granite specimen used for EGS reservoir simulation.

Fig. 5. Finite element model for stress uniformity evaluation.

Fig. 6. Modeled minimum horizontal stress profile traversing vertically through specimen's center.

Fig. 7. Modeled vertical and horizontal normal stresses with an assigned friction coefficient of 0.30 .

Fig. 8. AE source locations, estimated fracture location, and borehole locations for granite test. Fig. 9. Hydraulic data from the initial hydraulic fracture treatment.

Fig. 10. AE event locations during second hydraulic fracture re-stimulation.

Fig. 11. Summary of geothermal reservoir flow data.

Fig. 12. Example stepped constant pressure curve.

Fig. 13. Production rate to injection rate ratio as a function of injection rate.

Fig. 14. Digitized hydraulic fracture surfaces highlighting primary fractures (red) and secondary fracture (magenta). 


\section{Table 1}

List of sensors used during experimentation with their ranges and accuracies.

\begin{tabular}{|c|c|c|c|c|}
\hline Measurement & Mfg. and model & Purpose & $\begin{array}{l}\text { Measurement } \\
\text { Range }\end{array}$ & $\begin{array}{l}\text { Measurement } \\
\text { Accuracy }\end{array}$ \\
\hline Pressure & $\begin{array}{l}\text { Omega PX309- } \\
10 \mathrm{KG} 5 \mathrm{~V}\end{array}$ & $\begin{array}{l}\text { Wellhead, intermediate } \\
\text { confining jack pressure, } \\
\text { load frame pressure }\end{array}$ & 0 to $70 \mathrm{MPa}$ & $\pm 2 \% \mathrm{FSO}$ \\
\hline Pressure & $\begin{array}{l}\text { Omega PX309- } \\
3 \mathrm{KG} 5 \mathrm{~V}\end{array}$ & $\begin{array}{l}\text { Minimum confining jack } \\
\text { pressure }\end{array}$ & 0 to $20 \mathrm{MPa}$ & $\pm 2 \% \mathrm{FSO}$ \\
\hline Pressure & $\begin{array}{l}\text { Omega PX40- } \\
\text { 50BHG5V }\end{array}$ & $\begin{array}{l}\text { Outflow condensing } \\
\text { reservoir pressure }\end{array}$ & $0 \pm 6.7 \mathrm{kPa}$ & $\pm 0.95 \% \mathrm{FS}$ \\
\hline Temperature & $\begin{array}{l}\text { Omega TFE-T-24- } \\
500\end{array}$ & $\begin{array}{l}\text { General use type-T } \\
\text { thermocouple }\end{array}$ & -250 to $350{ }^{\circ} \mathrm{C}$ & $\begin{array}{l} \pm 0.5^{\circ} \mathrm{C} \text { or } \\
0.4 \%\end{array}$ \\
\hline Temperature & $\begin{array}{l}\text { Omega 5TC-GG-J- } \\
24-72\end{array}$ & $\begin{array}{l}\text { General use type-J } \\
\text { thermocouple }\end{array}$ & 0 to $750{ }^{\circ} \mathrm{C}$ & $\begin{array}{l} \pm 2.2^{\circ} \mathrm{C} \text { or } \\
0.75 \%\end{array}$ \\
\hline Strain & $\begin{array}{l}\text { Omega SGD- } \\
13 / 120-R Y 93\end{array}$ & $\begin{array}{l}\text { Sample surface strain } \\
\text { rosettes. }\end{array}$ & 0 to $30000 \mu \mathrm{s}$ & $\begin{array}{l} \pm(5 \%+\text { Temp } \\
\text { Effects })\end{array}$ \\
\hline Acoustic & $\begin{array}{l}\text { Physical Acoustics } \\
\text { Corporation WS } \alpha\end{array}$ & AE monitoring & 100 to $900 \mathrm{kHz}$ & $\begin{array}{l} \pm 1.5 \mathrm{~dB} \\
\text { directionality }\end{array}$ \\
\hline
\end{tabular}




\section{Table 2}

Material properties for Colorado Rose Red Granite.

\begin{tabular}{lll}
\hline Property & $\begin{array}{l}\text { Average } \\
\text { Value }\end{array}$ & $\begin{array}{l}\text { Standard } \\
\text { Deviation }\end{array}$ \\
\hline Unconfined Comp. Strength, UCS $(\mathrm{MPa})$ & $152^{\mathrm{a}}$ & 19 \\
Poisson's Ratio, $v$ & $0.32^{\mathrm{a}}$ & $\mathrm{N} / \mathrm{A}$ \\
Elastic Modulus, $E(\mathrm{GPa})$ & $56.9^{\mathrm{a}}$ & $\mathrm{N} / \mathrm{A}$ \\
Density, $\rho\left(\mathrm{g} / \mathrm{cm}^{3}\right)$ & $2.63^{\mathrm{a}}$ & 0.03 \\
Brazilian Tensile Strength, $B T S(\mathrm{MPa})$ & $7.5^{\mathrm{a}}$ & 1.8 \\
Notched Beam Fracture Toughness, NBFT $\left(\mathrm{MPa} \cdot \mathrm{m}^{0.5}\right)$ & 0.72 & 0.26 \\
Porosity, $\phi$ & 0.0077 & 0.0006 \\
Permeability, $K(\mu \mathrm{D})$ & $\leq 1.16$ & $\mathrm{~N} / \mathrm{A}$ \\
Specific Heat $\left(\mathrm{kJ} / \mathrm{m}^{3} \cdot \mathrm{K}\right)$ & 2063 & 92 \\
Thermal Conductivity $\left(\mathrm{W} \cdot \mathrm{m}^{-1} \cdot \mathrm{K}^{-1}\right)$ & 3.15 & 0.05 \\
Shear Wave Velocity, $V_{s}(\mathrm{~mm} / \mu \mathrm{s})$ & 2.62 & N/A \\
Compression Wave Velocity, $V_{p}(\mathrm{~mm} / \mu \mathrm{s})$ & 4.45 & N/A \\
\hline
\end{tabular}

${ }^{\mathrm{a}}$ Data includes tests performed by Colorado School of Mines Earth Mechanics Institute. 

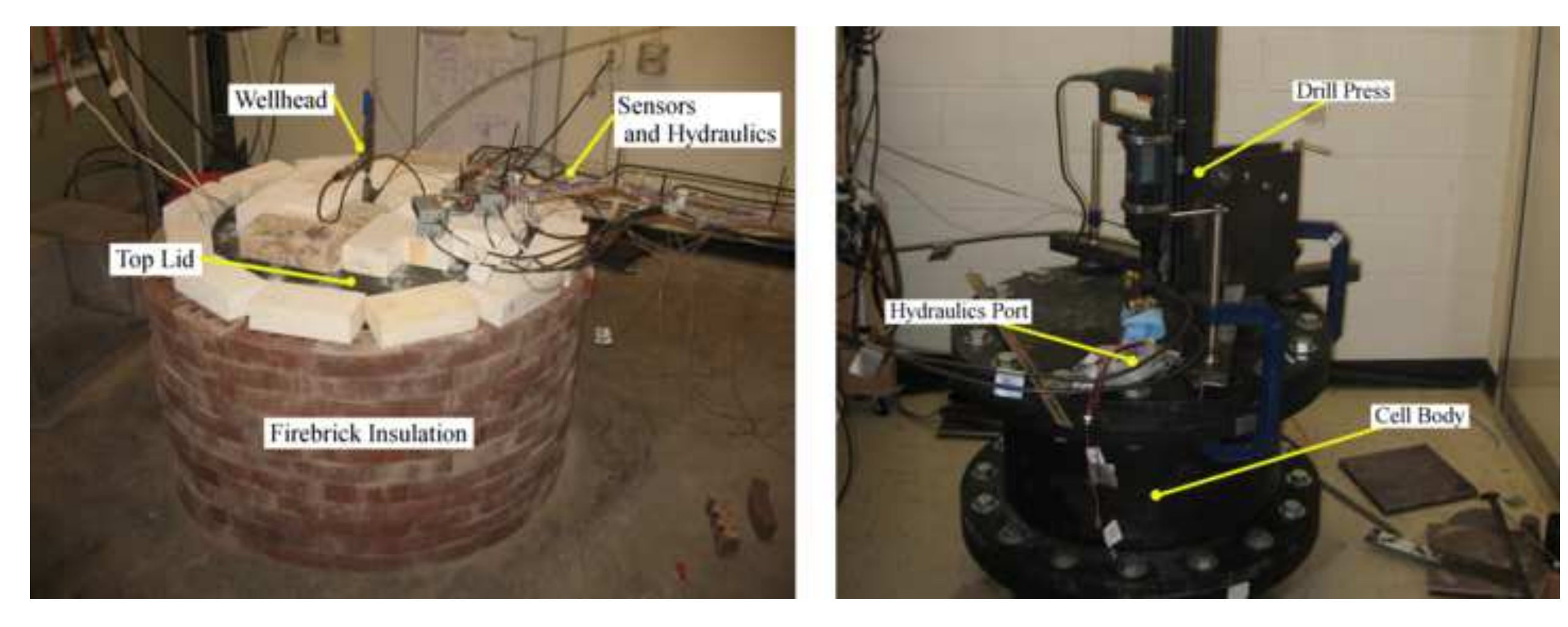

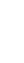

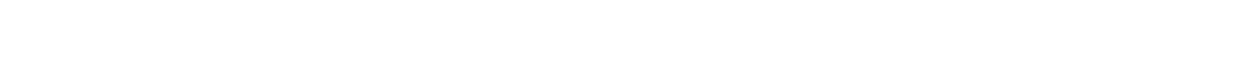


Stress Element

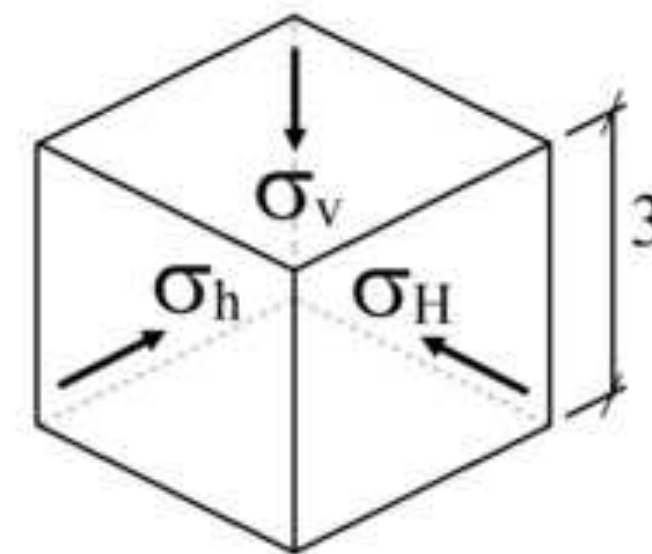

$300 \mathrm{~mm}$

$\mathrm{Cu}$.

Concrete Backing

Cylindrical Reaction Frame

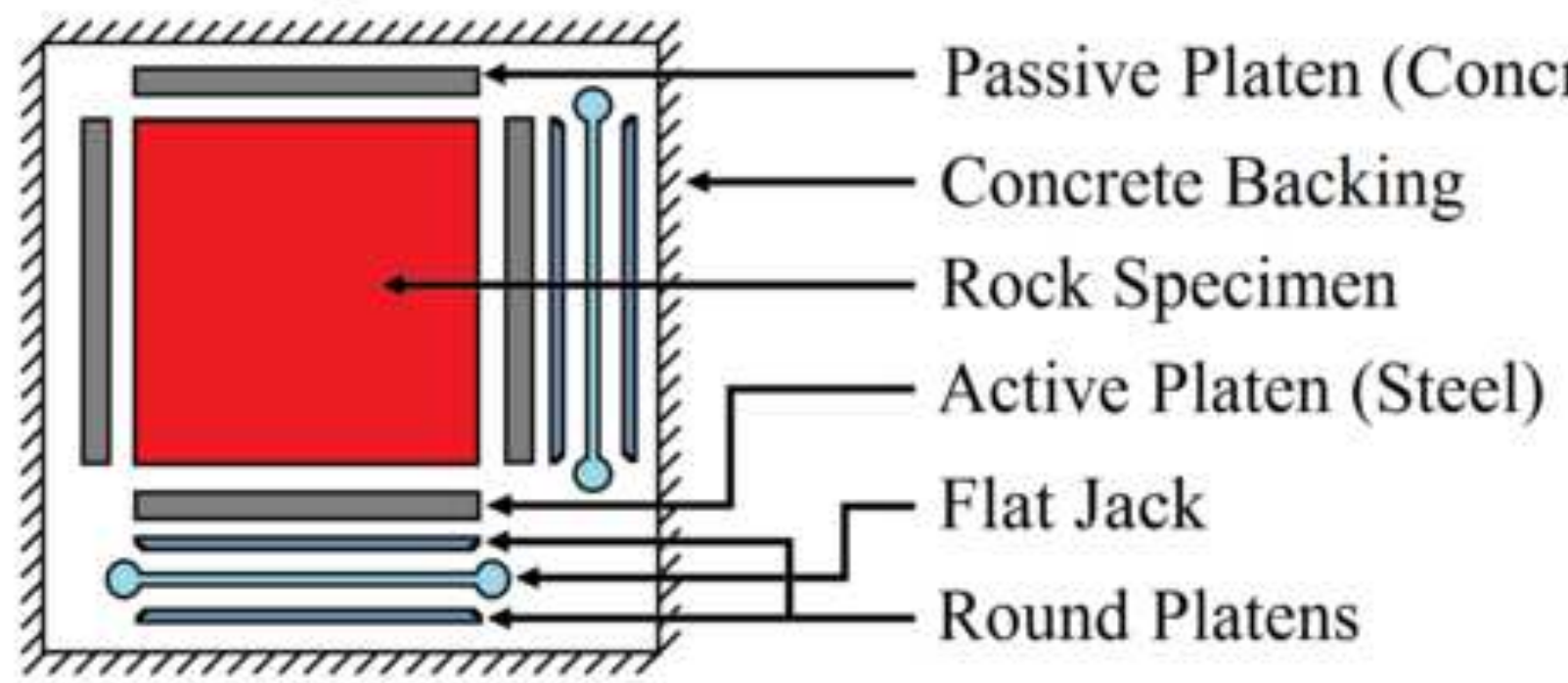

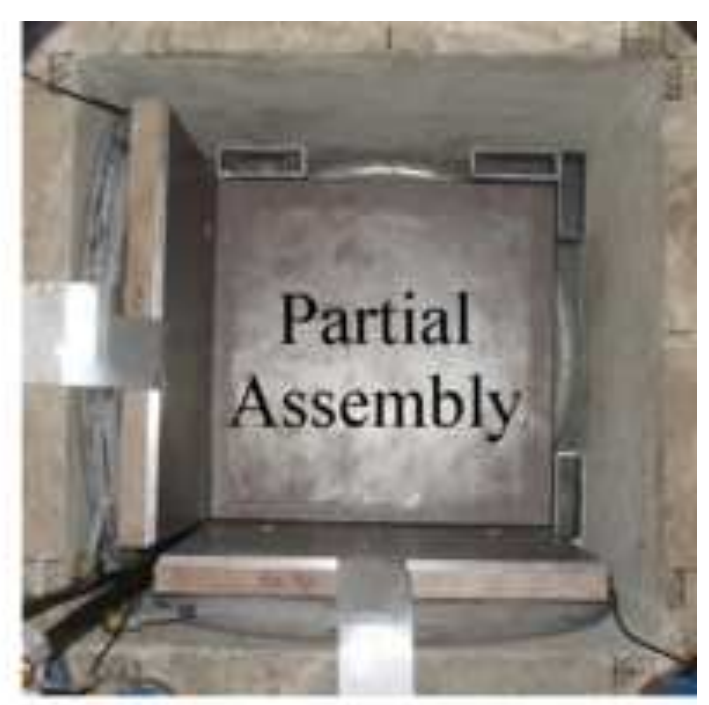

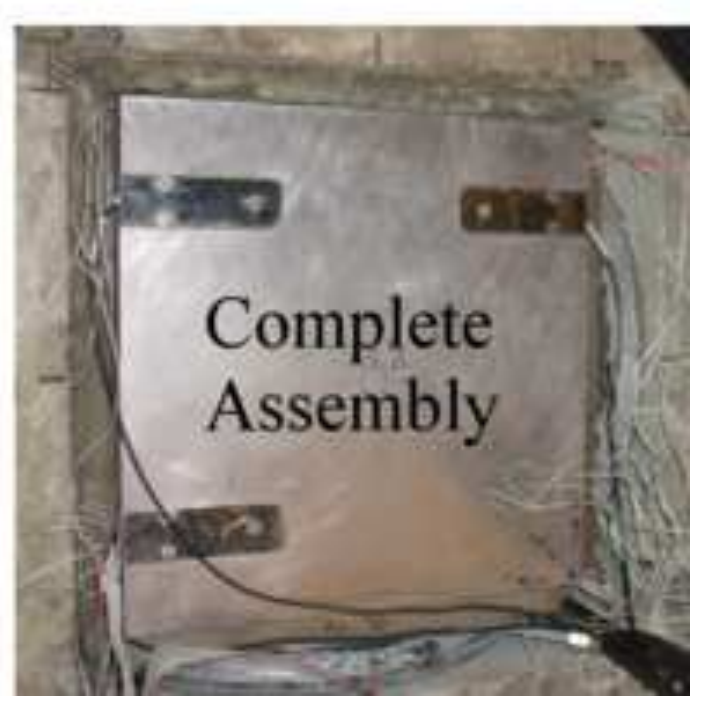



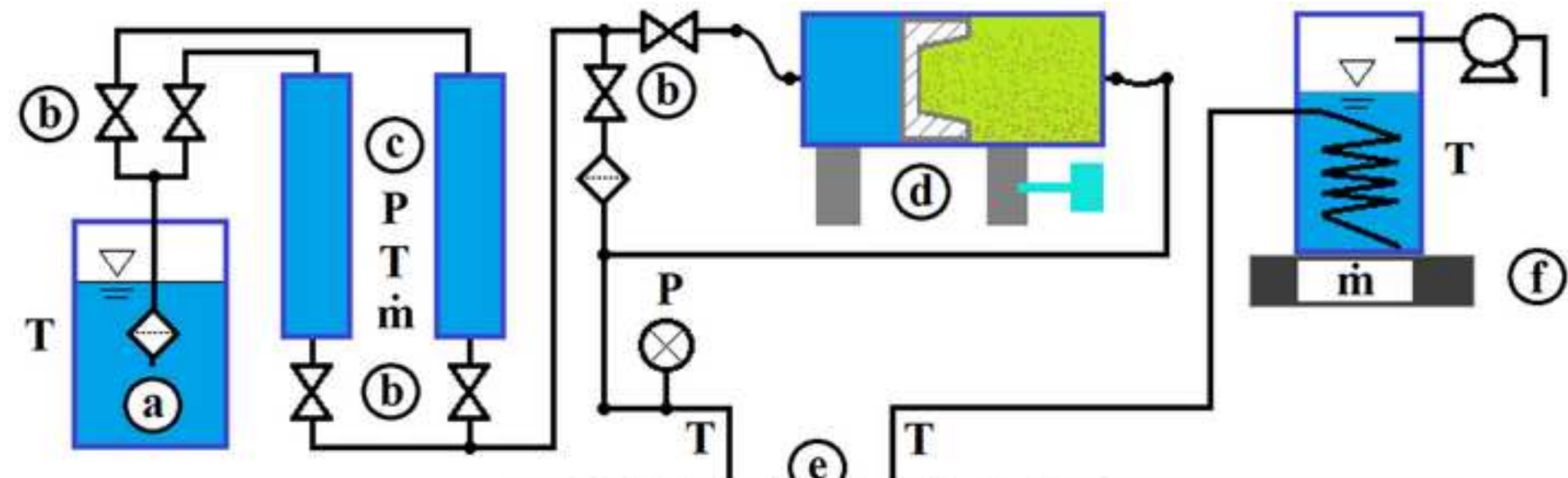

(g)
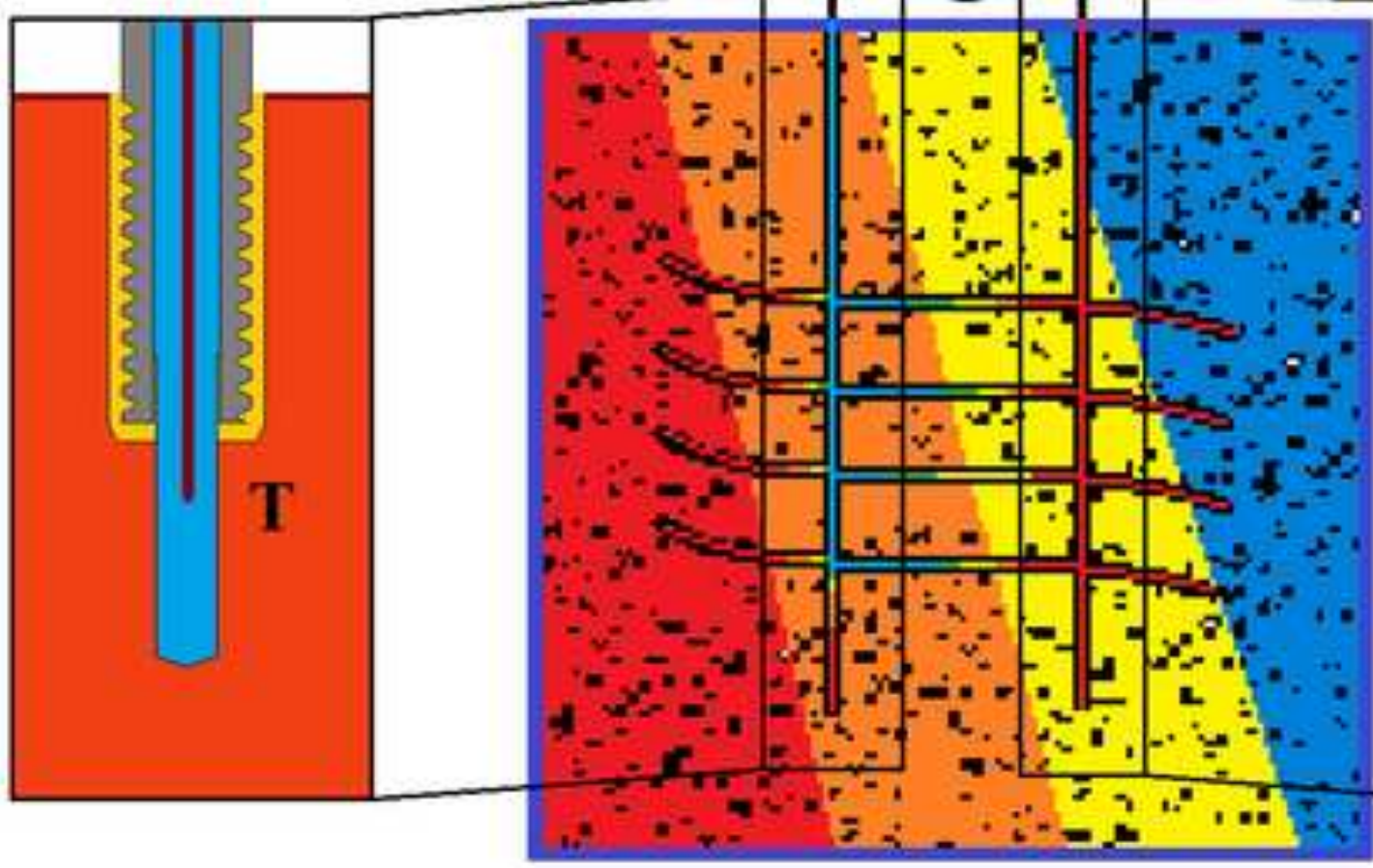

(b) 

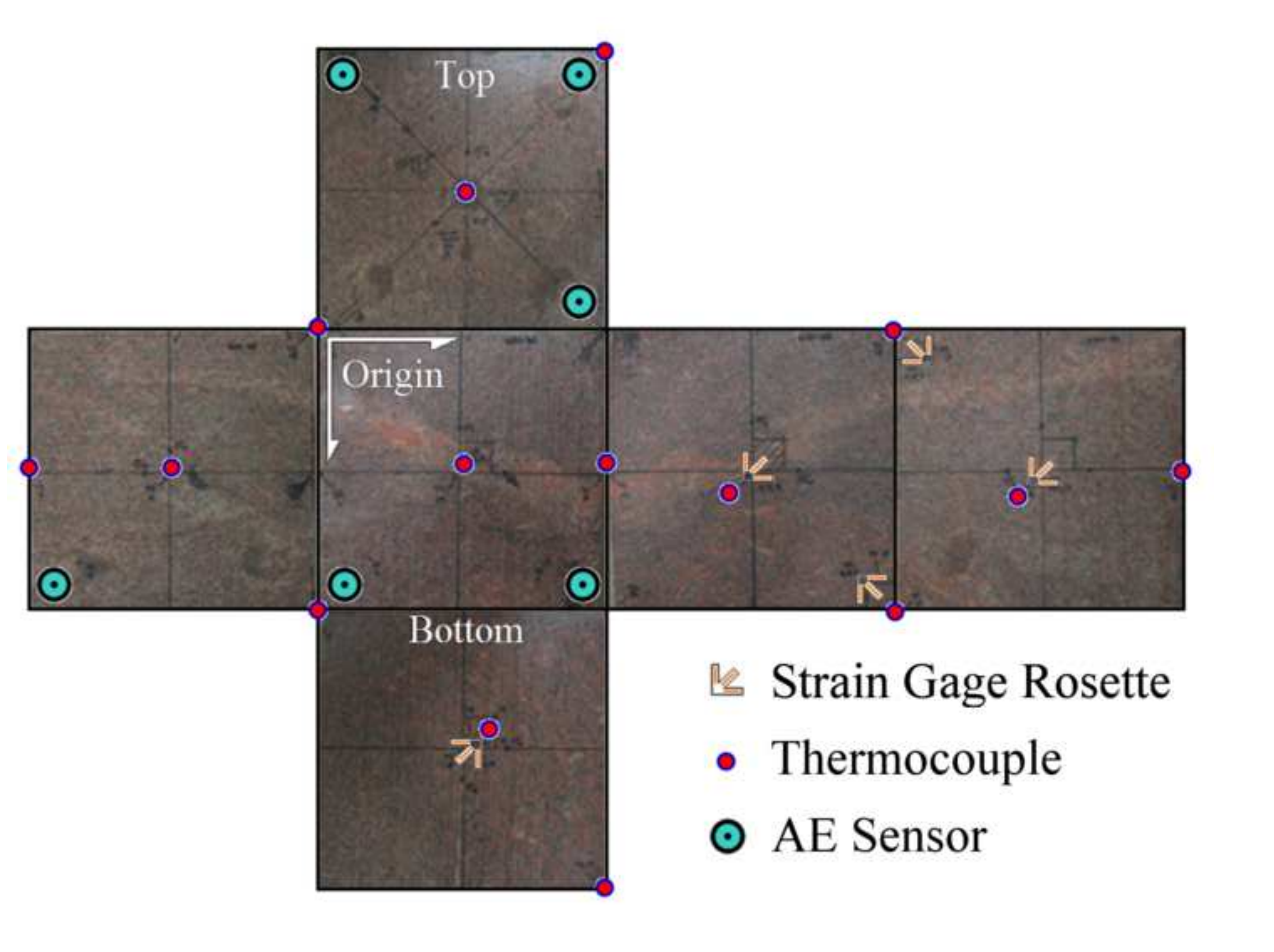

.

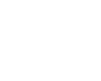



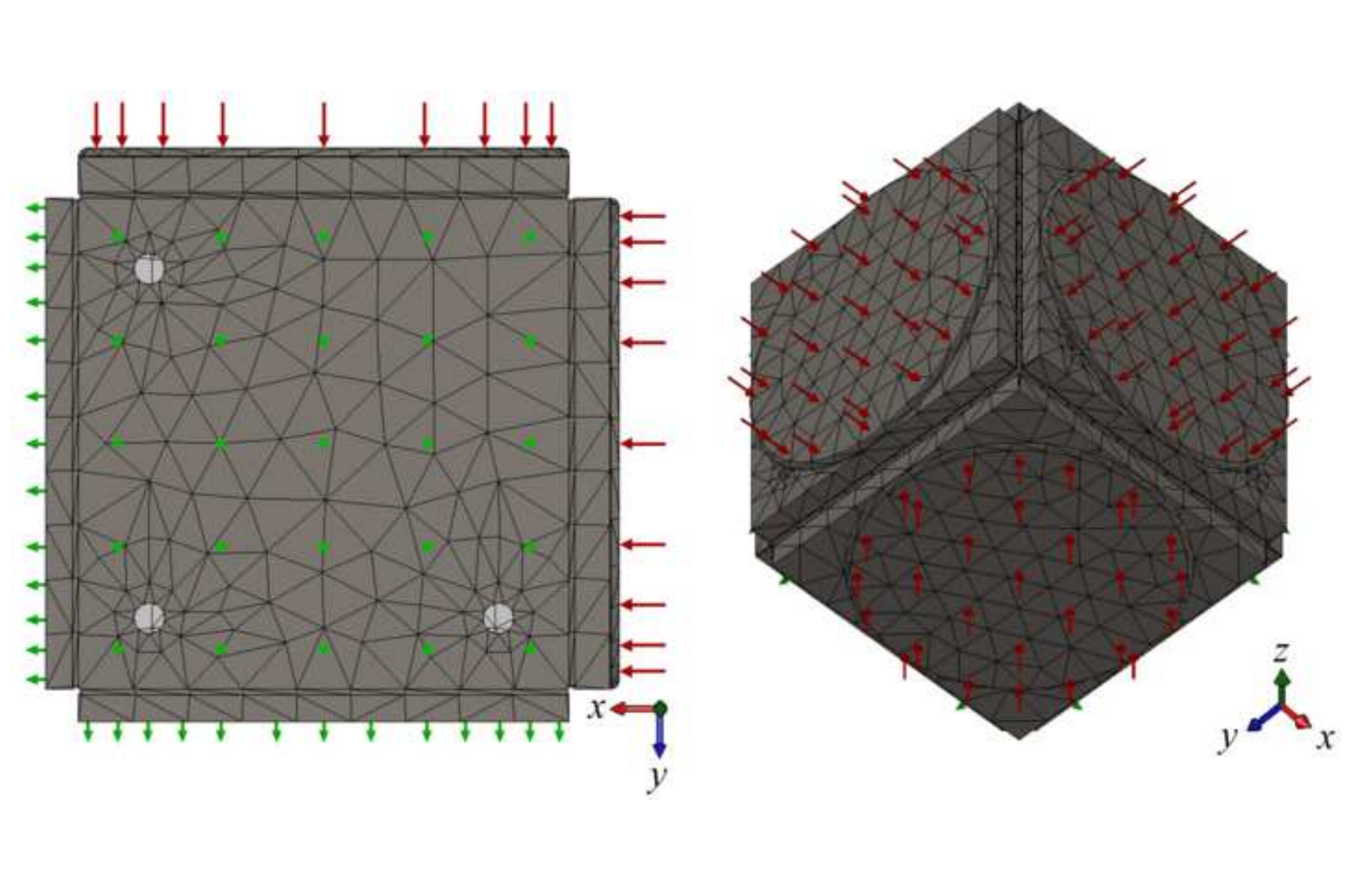
.

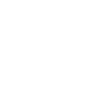

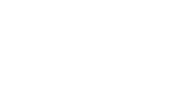

( 


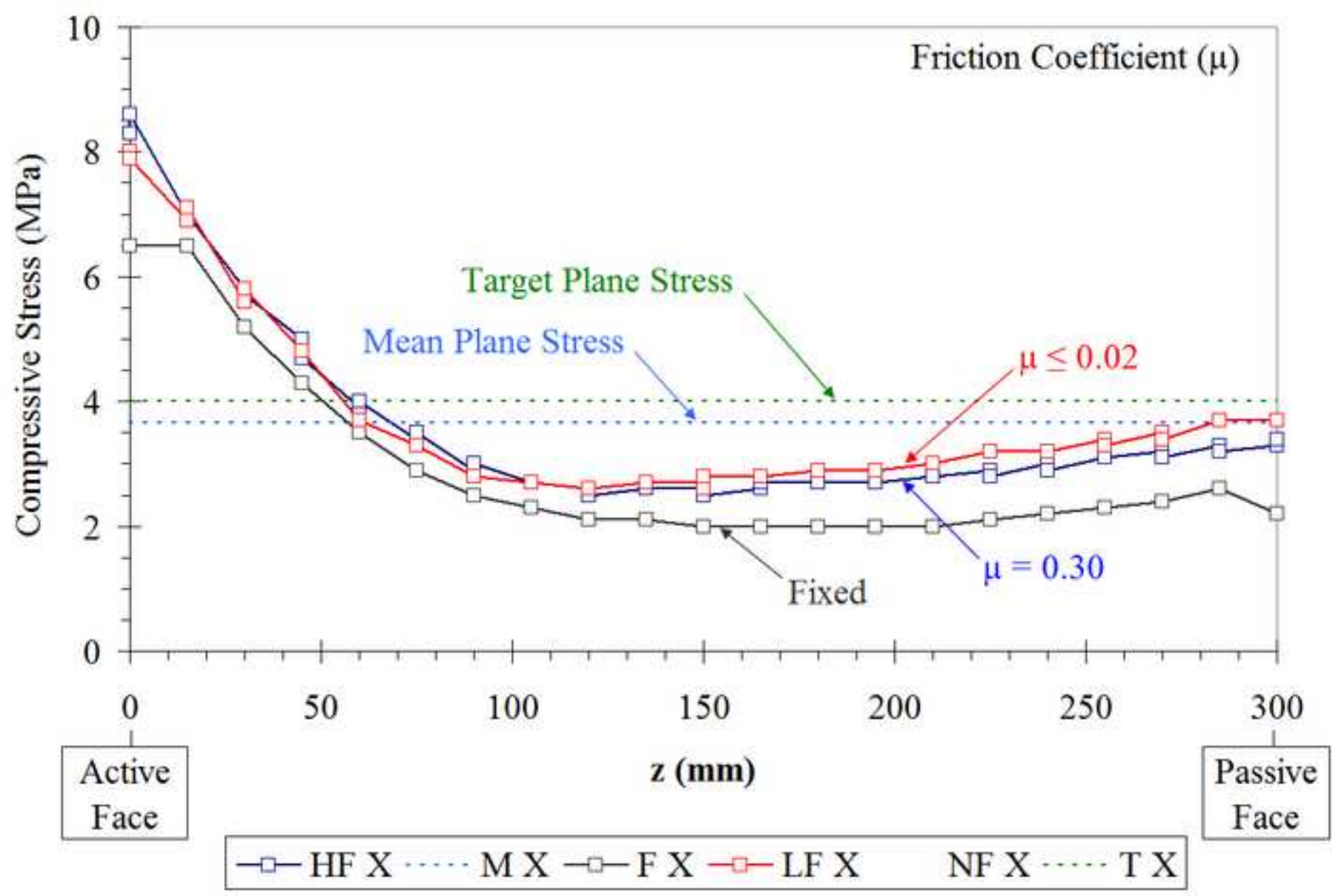




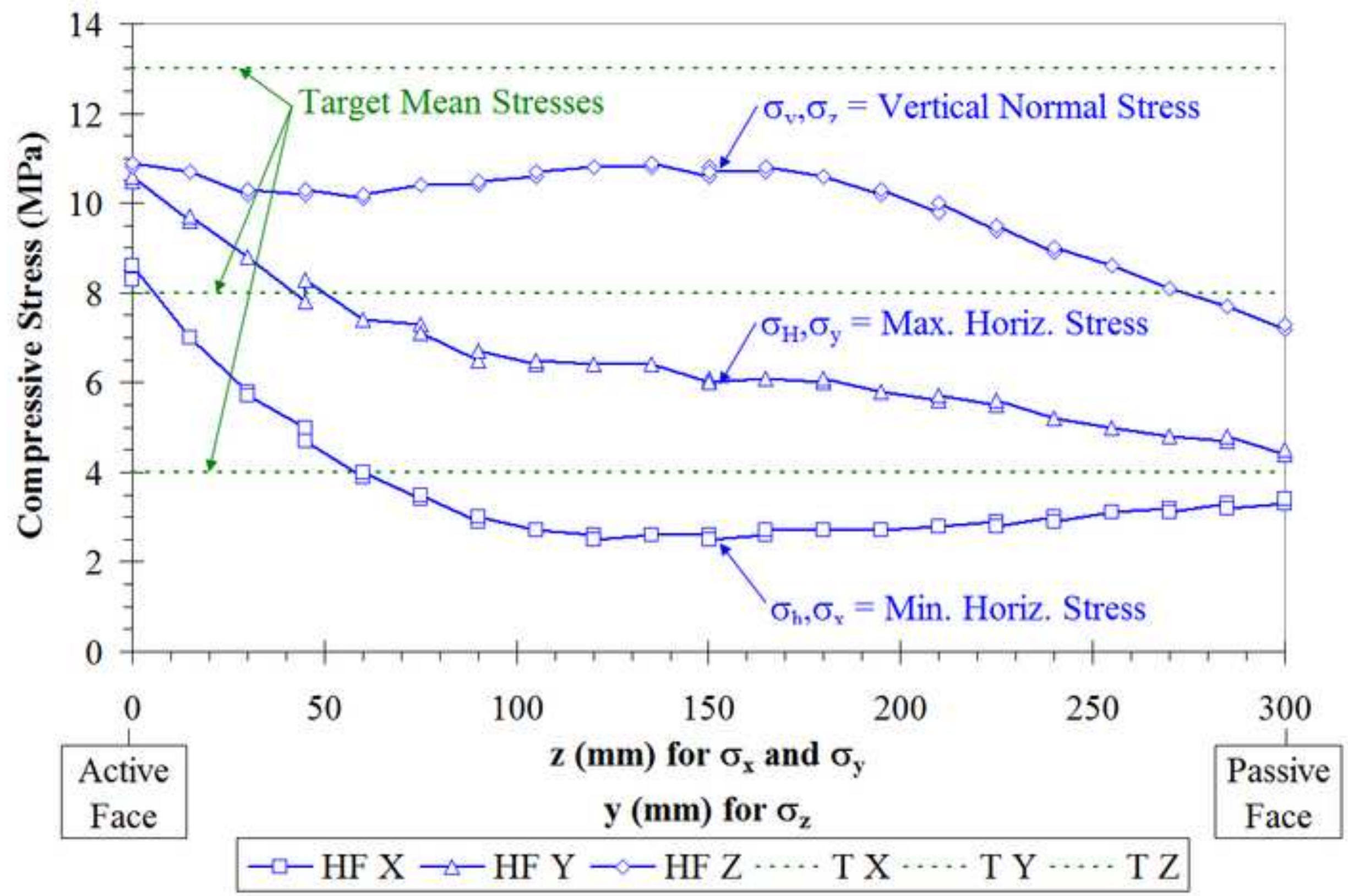




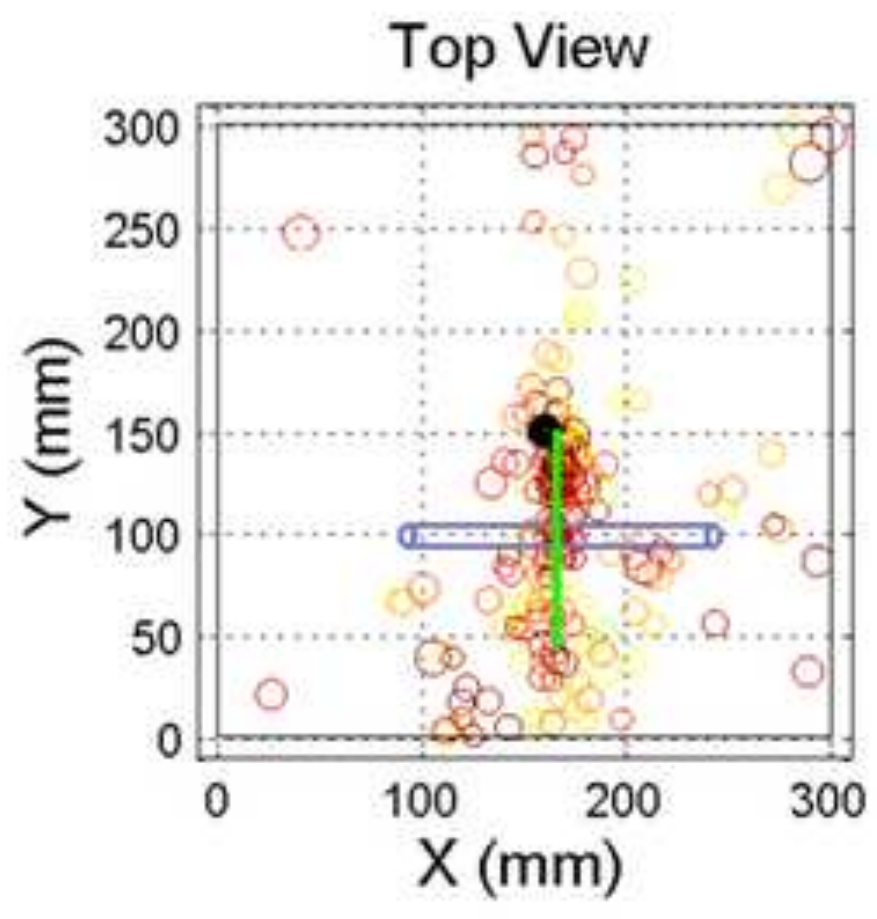

Front View

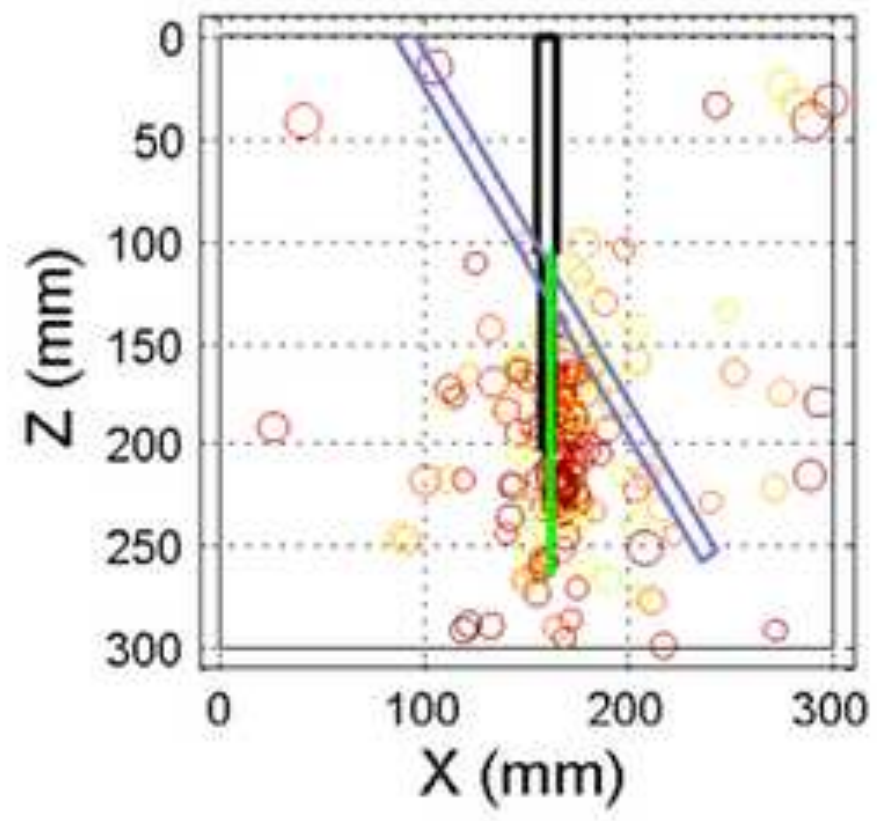

Isometric View

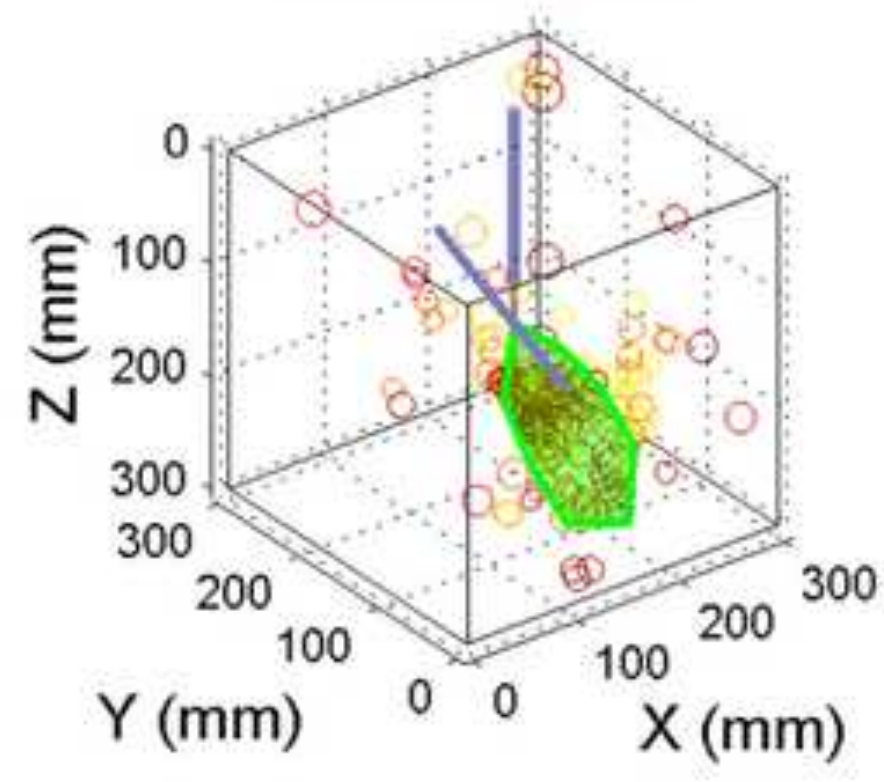

Side View

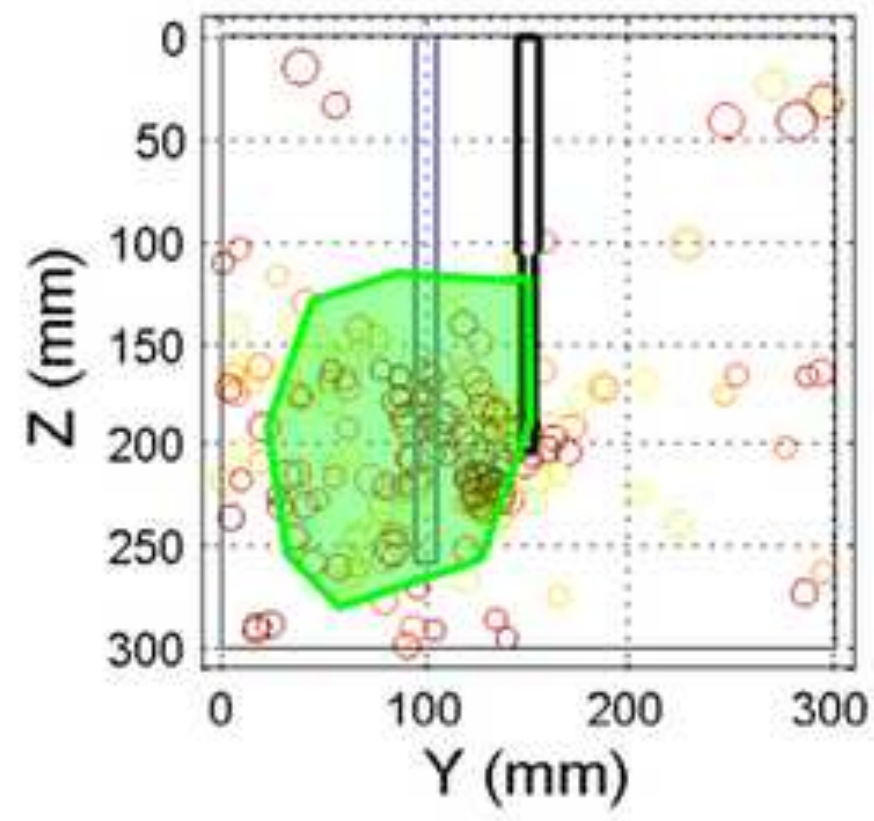




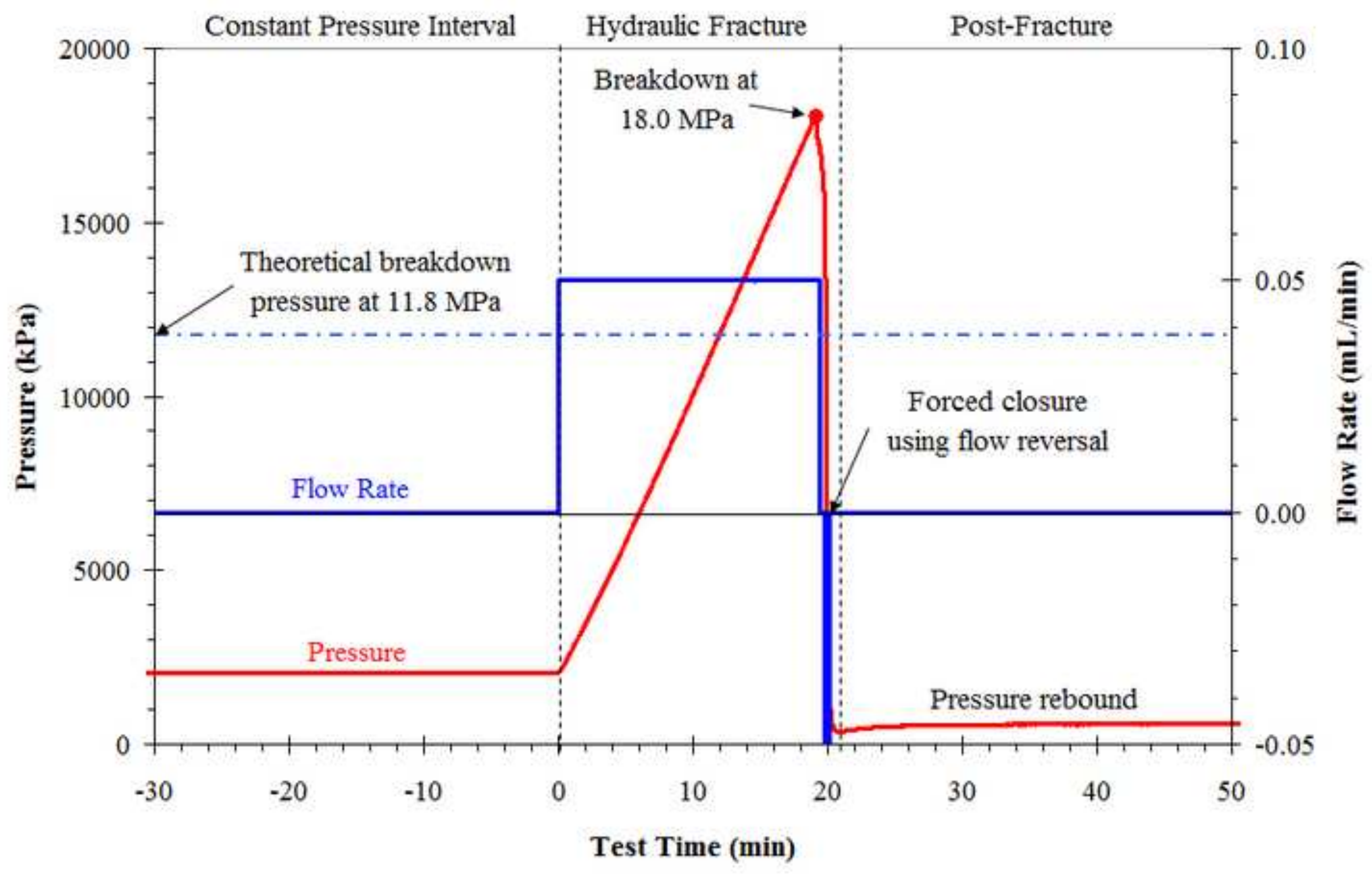


Top View

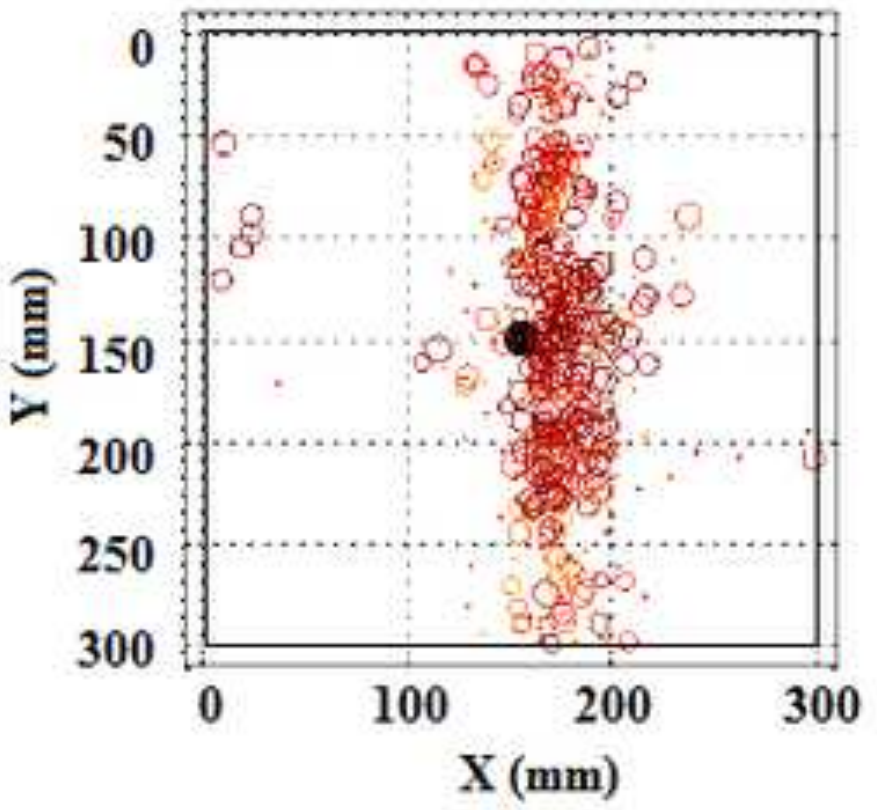

Front View

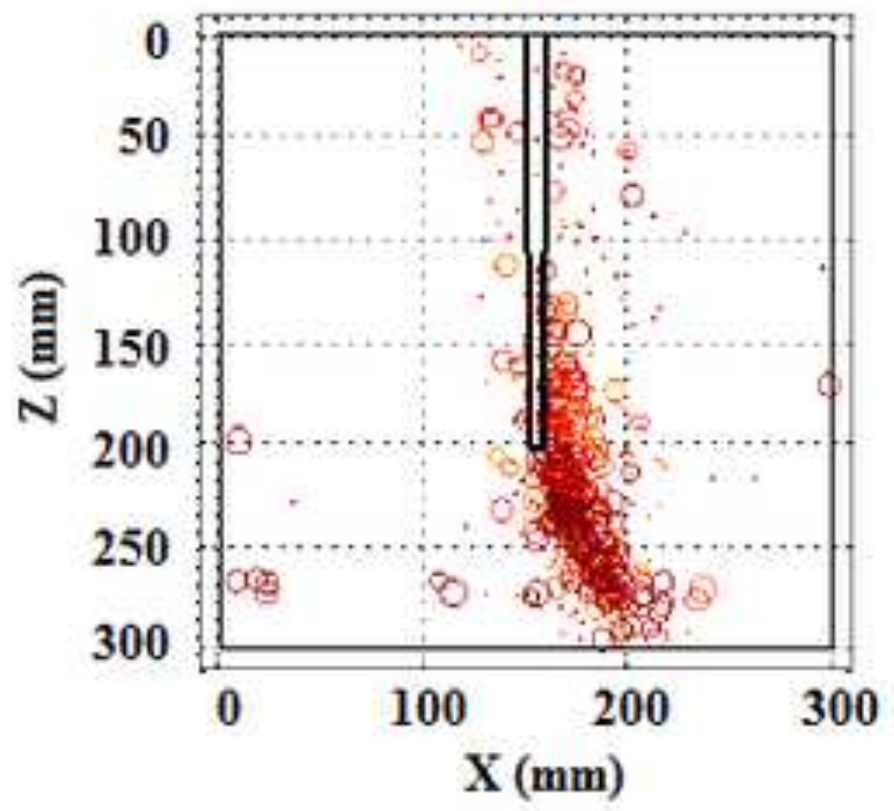

Oriented View

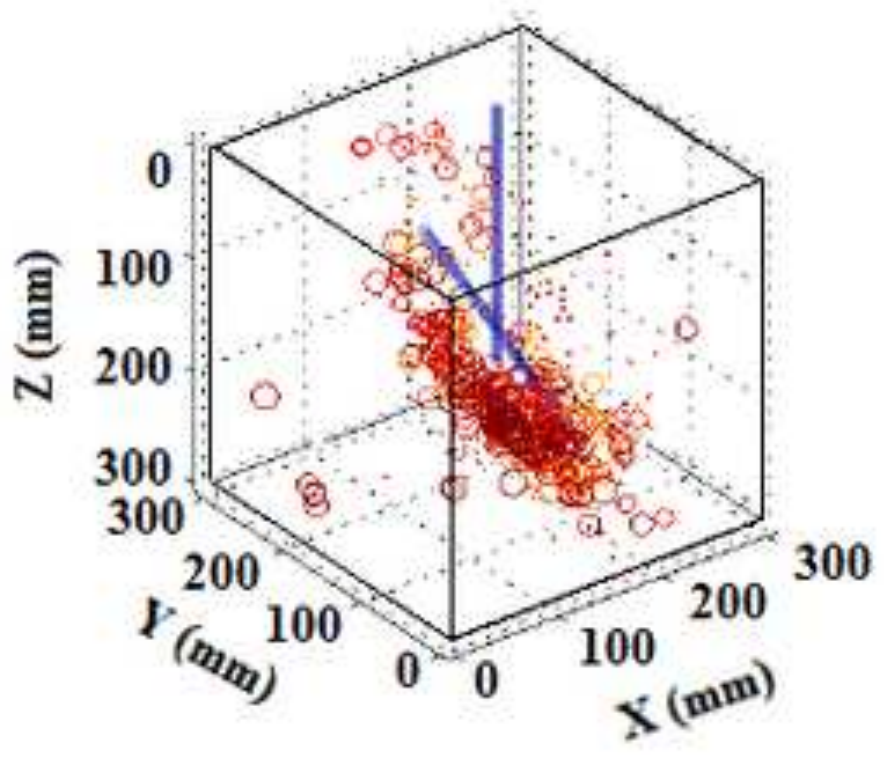

Side View

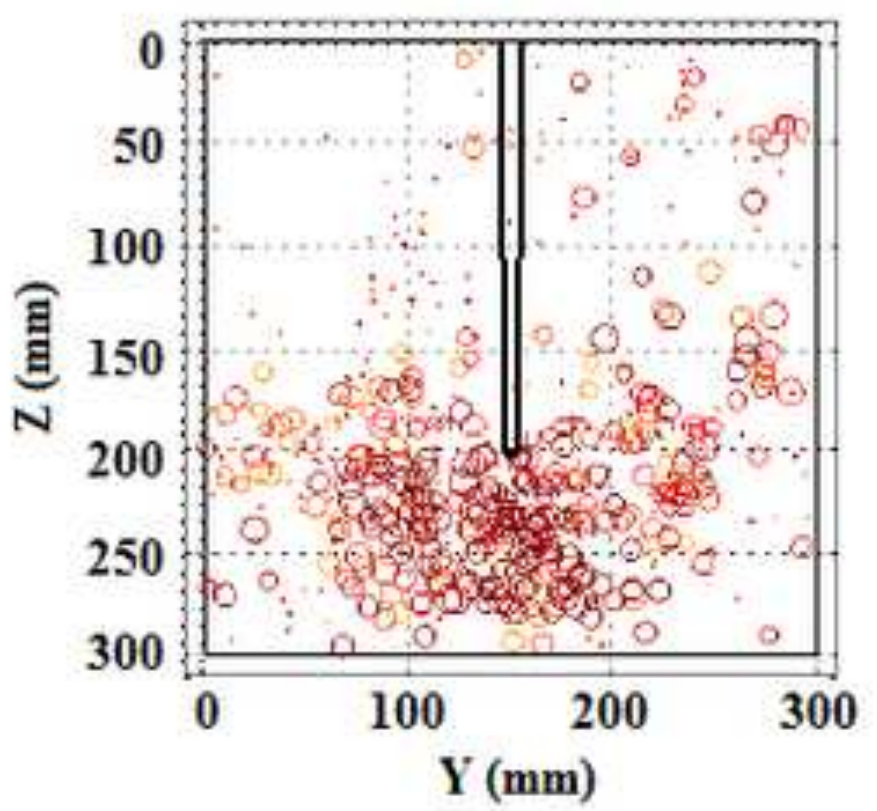




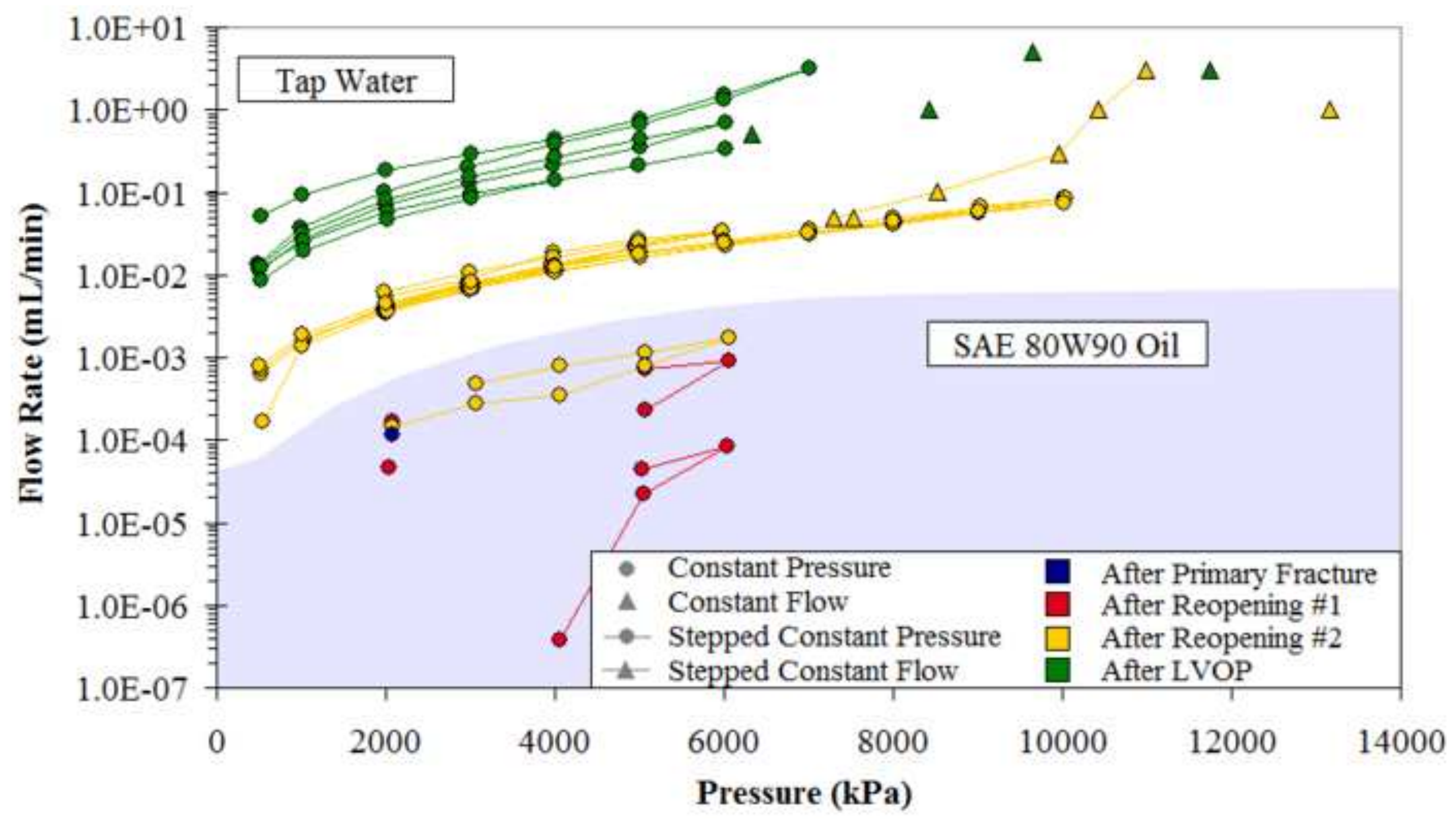




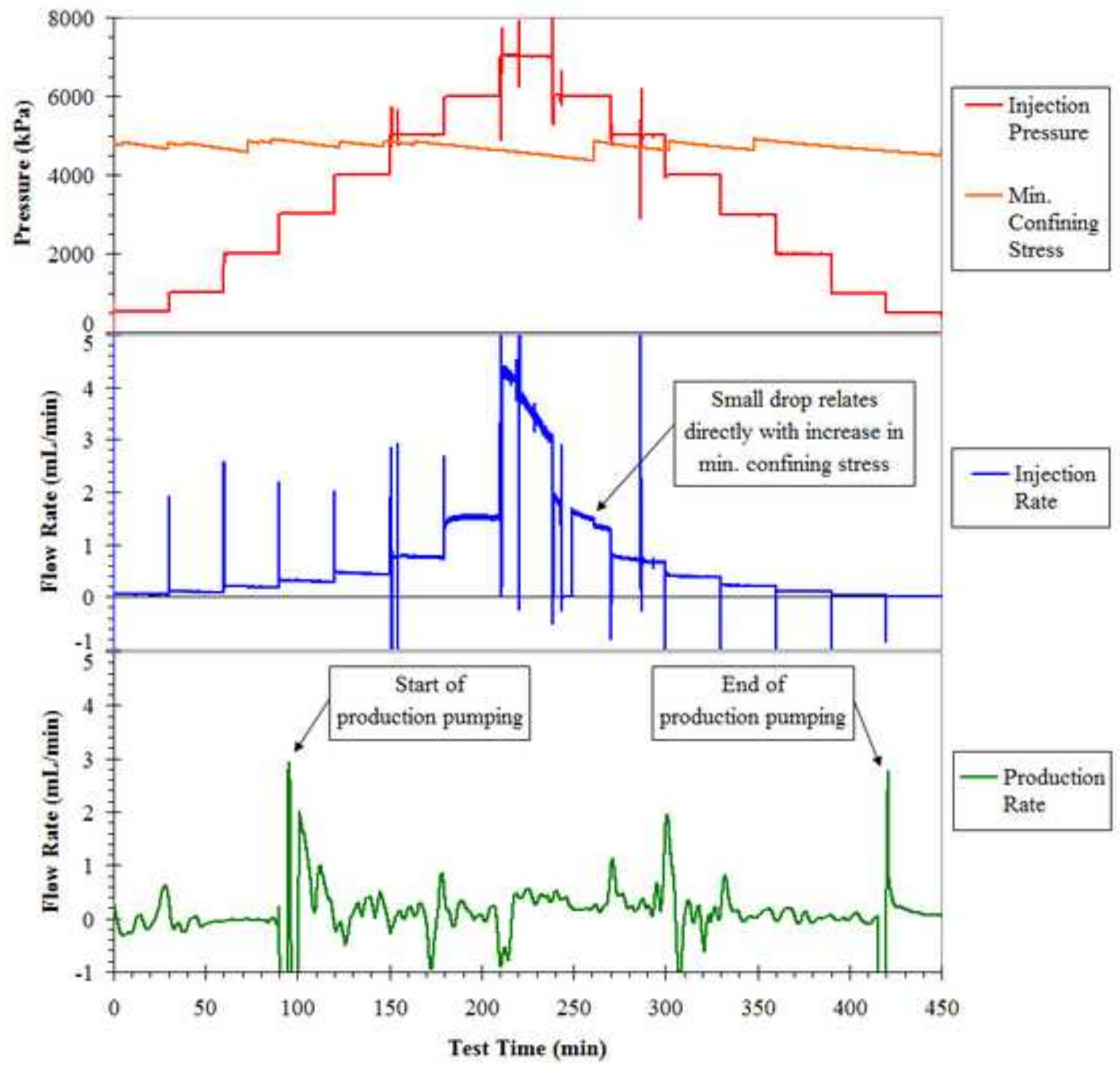




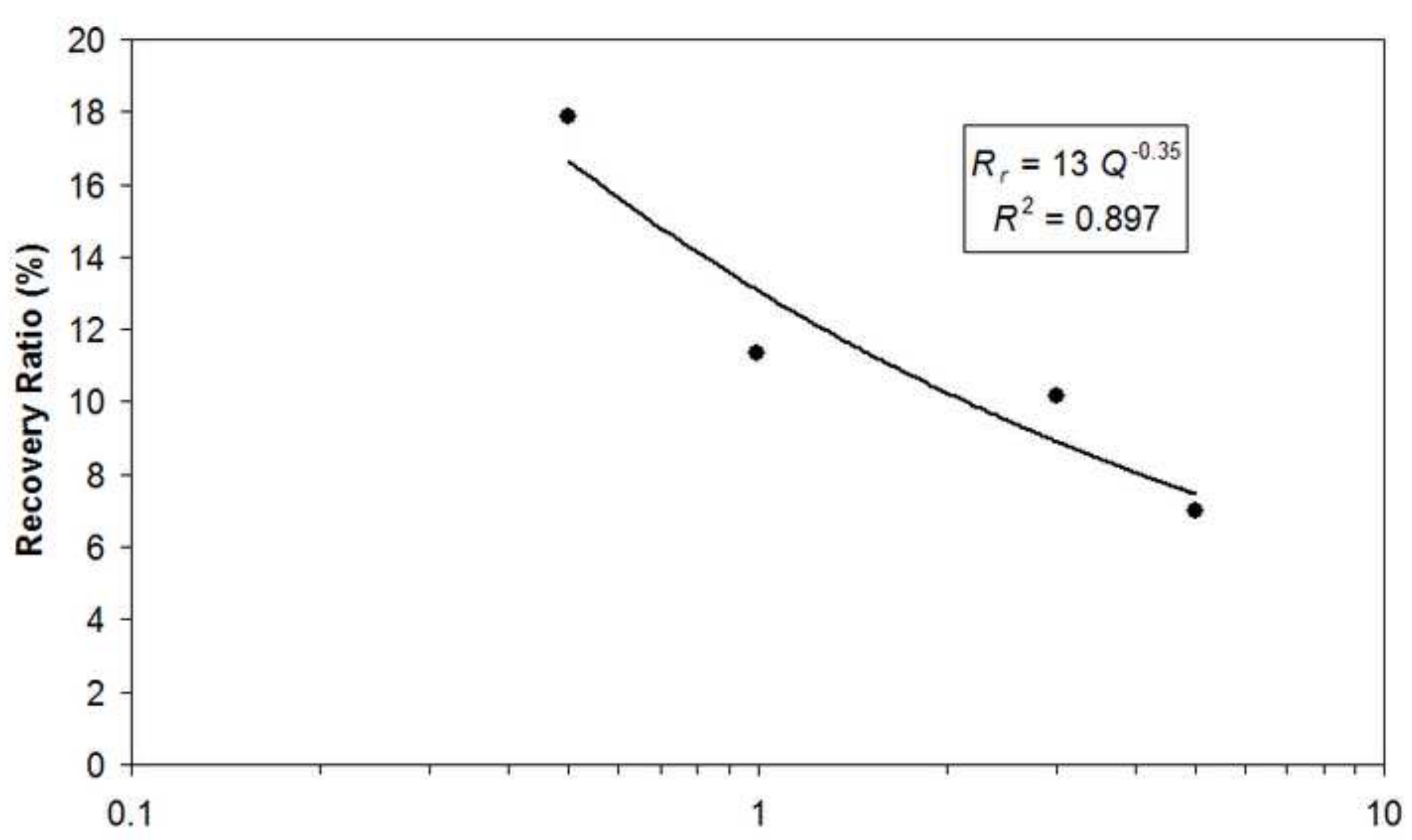

Flow Rate ( $\mathrm{mL} / \mathrm{min})$ 

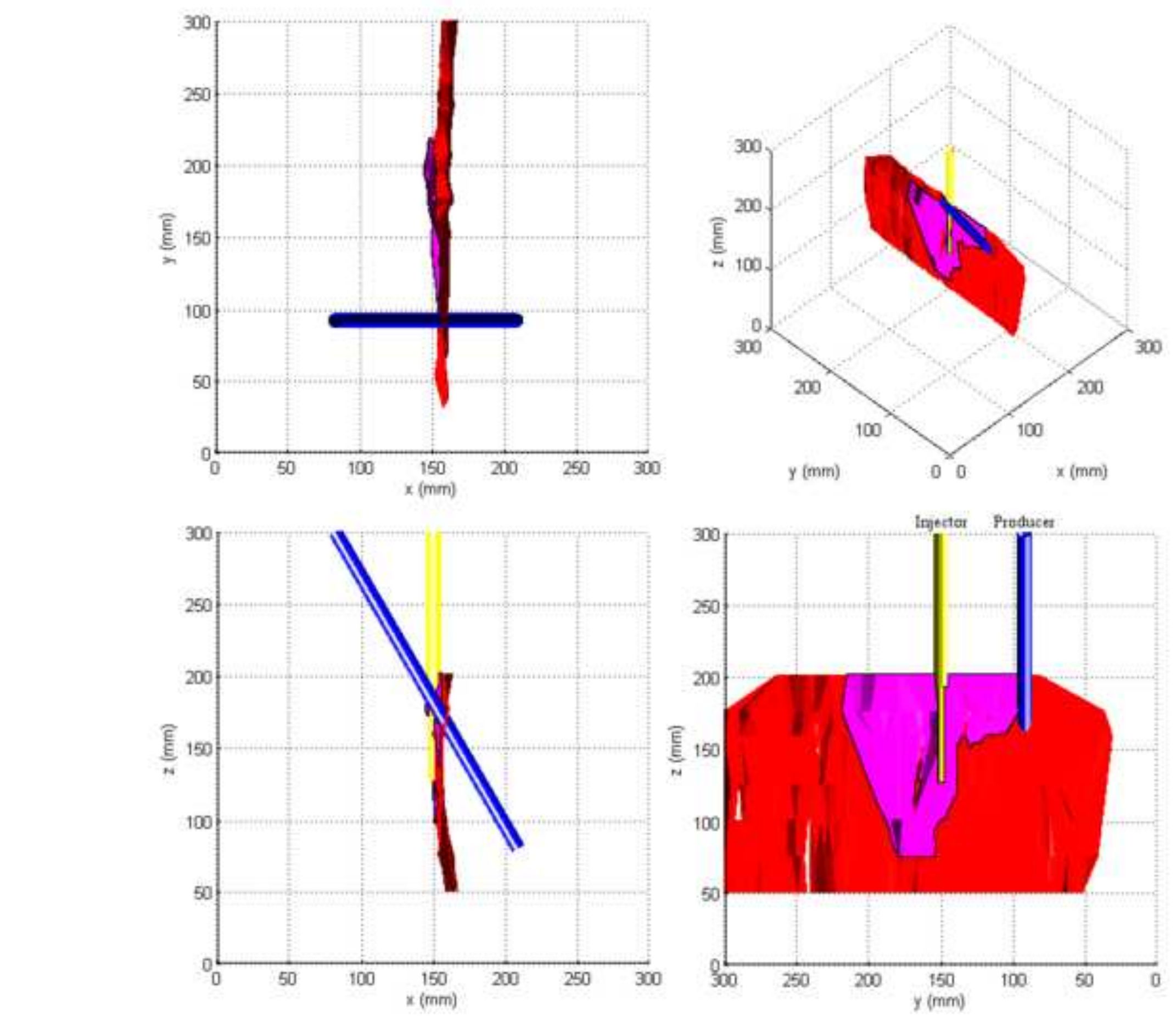

$$
\text { - }
$$

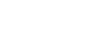

$$
\text { n }
$$$$
\text { (2) }
$$

$$
\text { (2) }
$$

